\section{Año 2019-2020. urtea} N. ${ }^{\circ} 31-32 . \mathrm{zk}$.

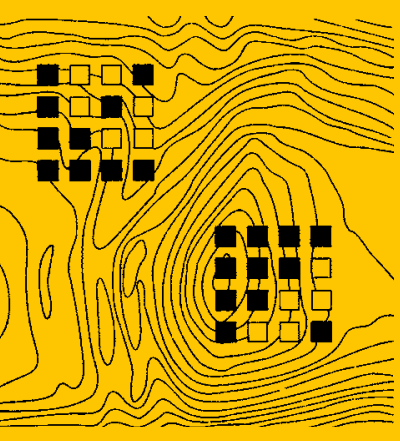

\section{TRABAJOS DE ARQUEOLOGÍA NAVARRA}

SEPARATA

\section{Una aproximación al conjunto calcolítico de Peña (Javier)}

Ángel A. Jordán Lorenzo, Lartaun López Pérez

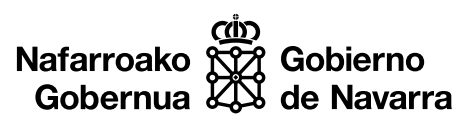

0000 


\title{
Una aproximación al conjunto calcolítico de Peña (Javier)
}

\author{
Hurbilketa bat Peñako (Xabier) multzo kalkolitikora
}

An Approximation to the Chalcolithic Group of Peña (Javier)

\author{
Ángel A. Jordán Lorenzo \\ Proyecto arqueológico de Cabeza Ladrero \\ ajordan@cabezaladrero.es \\ Lartaun López Pérez \\ UPV/EHU. Proyecto arqueológico de Cabeza Ladrero \\ lartaun89@gmail.com \\ DOI: https://doi.org/10.35462/TAN31-32.2
}

\begin{abstract}
Agradecimientos: Sara González, Iosu Barragán, Javier Muruzábal, Mari Carmen López, Alberto Jauregui, Lourdes Leoz, Jesús García Gazólaz, Jesús Sesma Sesma, Rubén Jiménez Gómez, Ulyses Palomino, Servicio Geológico de Navarra y José María León por su ayuda prestada.

El presente trabajo se integra en las actividades del Plan de Investigación que se viene llevando a cabo en el yacimiento arqueológico de Cabeza Ladrero (Sofuentes, Zaragoza) (http://www.cabezaladrero.es) con aprobación del Departamento de Educación y Cultura del Gobierno de Aragón, exp. n. ${ }^{\circ}$ 156/16/2017.
\end{abstract}




\section{RESUMEN}

En las siguientes páginas damos a conocer un conjunto de nueve sitios de cronología calcolítica identificados durante la III campaña de prospecciones en el término de Peña (Javier) y que se encuadran dentro del proyecto de investigación de Cabeza Ladrero (Sofuentes/Sos del Rey Católico, Zaragoza). Como el Calcolítico en Navarra es un periodo relativamente poco conocido, el objetivo de este trabajo es presentar este interesante grupo de sitios y realizar un primer acercamiento a ellos por medio de las herramientas SIG explorando con ello las posibilidades de interpretación que puede tener el registro de superficie.

Palabras clave: Cabeza Ladrero; Calcolítico; Peña; paisaje; prospecciones.

\section{LABURPENA}

Plazaratzen ditugun orrialde hauetan aurkezten dizkizuegu Peña barrutian (Xabier) egindako III. prospekzio kanpainan aurkitutako 9 aztarnategi berri, kronologia kalkolitikoa dutenak, eta Cabeza Ladreroko (Sofuentes/Sause, Zaragoza) ikerketa-proiektuaren barnean kokatuak daudenak. Kalkolitoa Nafarroan erlatiboki oso garai ezaguna ez denez gero, lan honen helburua da toki multzo interesgarri hau aurkeztea eta lehen hurbilketa bat egitea GIS tresnen bitartez. Modu horretan, lurrazaleko aztarnategiek dituzten interpretazio posibilitateak ikertuko dira.

Gako hitzak: Cabeza Ladrero; Kalkolitoa; Peña; paisaia; prospekzioak.

\section{ABSTRACT}

In the following pages we present a set of nine calcolithic sites identified during the III Survey Campaign in Peña (Javier) and which are part of the Cabeza Ladrero Research Project (Sofuentes / Sos del Rey Católico, Zaragoza). As the Chalcolithic in Navarra is a relatively unknown period, the objective of this work is to present this interesting group of sites and make a first approach through GIS tools, exploring with it the possibilities of interpretation that can have the surface record.

Keywords: Cabeza Ladrero; Chalcolithic; Peña; landscape; survey. 
1. INTRODUCCIÓN. 2. EL CALCOLÍTICO EN NAVARRA. 3. LA III CAMPAÑA DE PROSPECCIONES ARQUEOLÓGICAS. 4. INTERPRETACIÓN. 4.1. Aspectos generales. 4.2. Principales sitios atestiguados: Peña XIII y Peña X. 4.3. Asentamientos menores: Peña IV, Peña XI, Peña XII, Peña XV, Peña XXIII y Muga de Peña III. ¿Portillo Almadieros II? 4.4. Hacia una hipótesis de ocupación del territorio. 5. CONCLUSIONES. 6. LISTA DE REFERENCIAS.

\section{INTRODUCCIÓN}

Cabeza Ladrero es un yacimiento arqueológico de amplia cronología emplazado al sur del término municipal de Sos del Rey Católico (Zaragoza) y muy cerca de la localidad de Sofuentes, en el prepirineo aragonés (fig. 1). Para su ubicación se eligió un sitio estratégico formado por un conjunto de tres colinas que se levantan en el centro de un pequeño valle de 440 ha justo en la desembocadura del arroyo de Vallacuey con el barranco de Valdeoscura, sin duda un entorno idóneo para la disposición

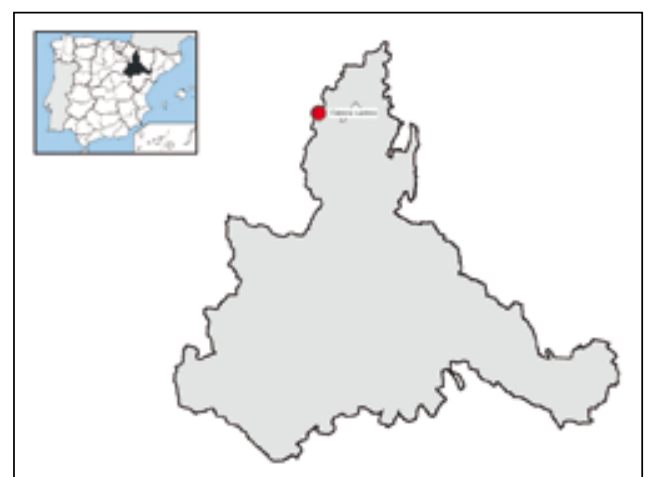

Figura 1. Localización del yacimiento de Cabeza Ladrero. de un asentamiento humano por cuanto que combina una fuente continua de agua con suelos ricos en nutrientes aptos para su explotación.

En este espacio desde el año 2016 se está desarrollando el «Proyecto Arqueológico de Cabeza Ladrero» con el objetivo de conocer tanto el yacimiento como su presumible área de influencia (Jordán, 2018b). Para ello se ha establecido un área de estudio de $370 \mathrm{~km}^{2}$ como zona de prospección en la que se pretende comprender las dinámicas de ocupación humana. Con ello se busca entender la forma de los asentamientos y caminos; cómo se establece la relación entre continuidad y cambio entre los diferentes 
sitios $^{1}$; o cómo interactuaron las diferentes comunidades que se identifiquen, tanto entre ellas como con el núcleo principal.

Este interés ha motivado la realización de, hasta el momento, seis campañas de prospecciones arqueológicas a lo largo de los años 2016-2020 que han permitido recorrer la totalidad del valle de Sofuentes, el valle de Mamillas (Sos del Rey Católico) y, ya en la Comunidad Foral de Navarra, el territorio comprendido por los barrancos de Valdelasviñas y Pintanés, en los términos de Javier y Cáseda. En este último contexto geográfico se ha podido identificar un conjunto de nueve sitios de cronología calcolítica durante la III campaña de prospecciones, realizada en 2017, que consideramos que guardan una estrecha interrelación pues, además de su cercanía espacial, muestran evidentes similitudes en su cultura material.

Dado que el Calcolítico en la zona es un periodo relativamente poco conocido (vid. Sesma, López, Mujika, Rodanés \& Vegas, 2009, p. 116 y $\$ 1$, a continuación), el objetivo de este trabajo es presentar este interesante grupo de sitios y realizar un primer acercamiento a ellos desde la óptica de la arqueología del territorio (Anschuetz, Wilshusen \& Scheick, 2001; Butzer, 2007; Deetz, 1990; Hodder \& Horton, 1990), por medio de las herramientas SIG (i. e. Gillings, 2015; Edeso \& Mujika, 2017).

\section{EL CALCOLÍTICO EN NAVARRA}

A pesar de que el estudio del Calcolítico en Navarra tiene una amplia trayectoria diacrónica pues los primeros hallazgos se dan a conocer a finales del siglo XIX por J. Iturralde y Suit (1911), puede considerarse que, en general, es una época poco conocida.

Durante las primeras décadas del siglo XX la investigación se centró en el conocimiento del fenómeno dolménico, especialmente en la zona noroccidental (estaciones de Ataun-Burunda, Altzania, Urbasa, Aritz-Belate, Lerate-Alkurruntz, etc.) y pirenaica (estaciones de Auritz/Burguete, Sorogain-Ibañeta, Abodi, etc.) gracias a las prospecciones de J. M. de Barandiarán, T. de Aranzadi, E. Eguren y F. Ansoleaga (Aranzadi \& Ansoleaga, 1915, 1918; Aranzadi, Barandiarán \& Eguren, 1920, 1921, 1923; Barandiarán, 1926). Además, se realizaron los primeros sondeos en las cuevas de Atabo y Abauntz (Vallespí, 1975), cuyo uso en el Calcolítico se dará a conocer en años posteriores como se verá más adelante.

La Guerra Civil supuso el cese de los trabajos hasta inicios de los años 40 momento en el que surgen nuevos investigadores como J. Elosegui, T. López Basurto, J. M. de Barandiarán (quien prospectó desde la década de los 40 culminando sus estudios en los

1 Entendiendo «sitio arqueológico» en el sentido de un lugar con aparición de estructuras o de objetos ligados a la presencia humana, con todos los condicionantes interpretativos que se desligan de la visión parcial del registro que se produce al analizar material de superficie (Leveau, 2000, p. 272). 
60) o J. Maluquer de Motes entre otros quienes, continuando con la tradición anterior, se centraron casi con exclusividad en el análisis del fenómeno dolménico².

En las décadas de los 70 y 80 estudiosos como I. Barandiarán y E. Vallespi (Barandiarán \& Vallespí, 1982; Vallespi, 1975) comenzaron a realizar las principales recopilaciones de toda la información que había hasta la fecha, desarrollándose excavaciones por toda Navarra con las nuevas técnicas y metodologías. Gracias a ello se avanzó en el conocimiento del megalitismo navarro, contextualizándolo con el de otras regiones de la península ibérica (Beguiristáin, 1976; Cava, 1984; Ezkurdia, 1987) y se afianzaron tipologías como los túmulos (Ondarra, 1975a, 1975b, 1976a, 1976b, 1982, 1988) o cistas (Andrés, 1977, 1978, 1979, 1986), a la par que se empezó a prestar una mayor atención al fenómeno de los yacimientos al aire libre (Beguiristáin, 1980, 1982) o las ocupaciones en cuevas/abrigos, como la de Abauntz (Utrilla, 1977, 1979, 1982), Padre Areso o el Nacedero de Riezu (Beguiristáin, 1979, 1987).

A partir de este momento y durante las últimas décadas gracias al programa sistemático de prospecciones arqueológicas encuadradas en el Inventario Arqueológico de Navarra y a la realización de diversas excavaciones es posible dibujar un mapa más completo del Calcolítico en Navarra aunque, por desgracia, centrado sobre todo en la identificación de sitios, más que en el ahondamiento cultural.

De esta forma y continuando con la rica tradición anterior, se ha comprobado la extensión del fenómeno del megalitismo a prácticamente todo el territorio foral (Armendáriz, 1999; Beguiristáin \& Albisu, 2003; Beguiristáin, Vélaz, Unanua \& Álvarez, 2007; Irigaray \& Armendáriz, 1993-94, 1995; Ondarra, 1991-92; Sesma, Andrés \& García, 1997; Sesma, García, Beguiristáin \& Sinues, 1993-1994), al igual que ocurre con los enterramientos en cistas (Sesma \& García García, 2006, 2012; Sesma et al., 2014) y en cuevas/abrigos (Cava \& Beguiristáin, 1991-92).

Del mismo modo algo se ha avanzado en la catalogación y conocimiento de los yacimientos al aire libre (Beguiristáin, 1990; Unanua \& Erce, 2014), aunque solo se han excavado hasta el momento los yacimientos de Las Facerias (Sesma \& García Gazólaz, 1995-96), Paternainbidea (García Gazólaz, 1998), Lorkazarra (Ramos, 2009) y Aspra (Erce \& Unanua, 2013).

Por último, cabe resaltar la existencia de trabajos más específicos centrados en la cultura material (García Gazólaz, 1993; García Gazólaz \& Sesma, 2009), así como aportaciones tangenciales de carácter recopilatorio (Armendáriz, 2008; Nuin \& Borja, 1991).

Así, en conclusión, como se puede ver el Calcolítico se trata de una época bien conocida en Navarra solo en algunos aspectos como consecuencia de las pocas excavaciones

2 Así J. M. Sansinenea (1950), F. Ripa (1952), J. Elosegui (1952, 1953a, 1953b, 1962), L. Peña Basurto (1954), T. López Selles (1957, 1959a, 1959b, 1960, 1961), J. M. de Barandiaran (1962), J. Maluquer de Motes (1955, 1962, 1964, 1965). 
realizadas, con una gran comprensión del mundo funerario de este periodo, pero un notable vacío en el conocimiento de la sociedad. En relación con ello nuestro estudio pretende ser una apertura hacia nuevas posibilidades investigadoras que permitan avanzar un poco más en el conocimiento de esta época.

\section{LA III CAMPAÑA DE PROSPECCIONES ARQUEOLÓGICAS}

La III campaña de prospecciones arqueológicas en el entorno de la ciudad de Cabeza Ladrero, en cuyo contexto se identificaron los sitios que estudiamos en estas hojas, se realizó entre septiembre y diciembre de 2017 en un área de prospección de 16 km². Los límites se definieron al norte por las estribaciones meridionales de la sierra de Sofuentes/Santo Domingo; al sur por el canal de las Bardenas; al este por la frontera con la provincia de Zaragoza y la sierra de Peña; y al oeste por la Val de la Cañada (fig. 2) ${ }^{3}$.

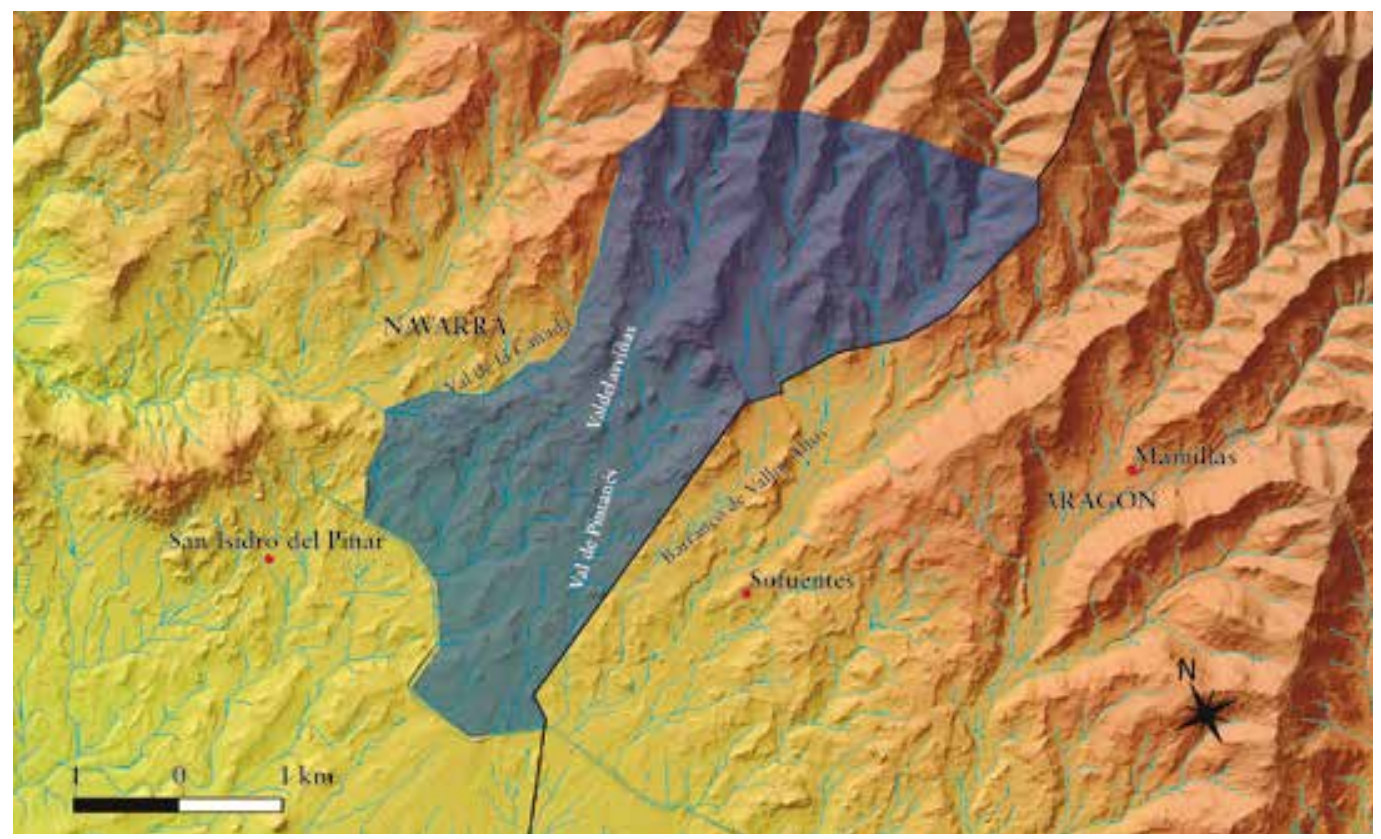

Figura 2. Delimitación de la zona de prospección.

Desde un punto de vista geológico el territorio recorrido se inscribe en una zona de formación miocénica situada en las estribaciones meridionales de la sierra de Santo Domingo. Está caracterizado por la presencia de limolitas y arcillas con alguna pequeña surgencia de areniscas que se sitúan entre barrancos naturales que discurren en dirección N-S creando

3 Prospecciones realizadas con la colaboración de Sara González, Iosu Barragán, Javier Muruzábal, Mari Carmen López, Alberto Jauregui y Lourdes Leoz, a quienes desde aquí queremos agradecer toda su ayuda. 
depósitos de gravas, arenas y limos. De entre los barrancos naturales destacan los de Pintanés y Valdelasviñas situados en el centro del área de prospección. Así su tramo medio fluye en paralelo, aunque los separa una cresta rocosa de $507 \mathrm{~m}$ de altura. El barranco de Valdelasviñas es el más largo de los dos con una longitud de $8 \mathrm{~km}$ y recoge las aguas de ambos lados de la val homónima desde la propia sierra de Santo Domingo en las puntas de Valdecilla, La Erica y Valdeviñas. Por su parte el barranco de Pintanés tiene una extensión de $4 \mathrm{~km}$ y se genera con las aguas procedentes de la zona meridional de El Rinconaz y a unos 2,5 km se junta con el barranco de Vallos Altos, que procede de la Val de Sofuentes.

La zona a recorrer ya había sido prospectada en 2001 por la empresa Olcairum en el contexto de la realización de las prospecciones arqueológicas del término de Javier para el Inventario Arqueológico de Navarra (IAN), mientras que el espacio correspondiente al término municipal de Cáseda se efectuó en dos ocasiones (1991 y 2015) para el IAN también por la misma empresa, por lo que gran parte de los sitios que se van a presentar en estas hojas ya se conocían desde entonces ( $c f r$. VV. AA., 2001). Por esta razón uno de los objetivos de las prospecciones fue confirmar los sitios ya existentes, aspecto este que pudo realizarse en todos los casos con excepción de los sitios de Peña XII, Peña XX y Peña XXVI, en los que las condiciones del campo impedían su visibilidad y Peña XIX, donde no se encontró material en superficie ${ }^{4}$.

Los trabajos actuales se hicieron planteando como unidad principal de prospección la parcela, definida cartográficamente en los mapas catastrales y en la fotografía aérea y, sobre el terreno, por los límites de los ribazos y lindes de los campos (Burillo, Ibáñez \& Alegre, 2005, p. 171; Mayoral, Cerrillo \& Celestino, 2009, p. 12; Pardo-Gordó et al., 2017, p. 188). En ellas se plantearon transeptos con intervalos de cinco metros de media entre prospectores aunque su distancia podía variar dependiendo del tamaño de la parcela y de la aparición o no de material.

El material identificado en el campo se ha georreferenciado utilizando para ello los propios dispositivos GPS con que cuentan los actuales teléfonos móviles y que proporcionan un margen de error de entre 3 y 4 metros, algo aceptable para la geolocalización de material en superficie. Además, a cada pieza encontrada se le ha realizado una ficha sobre el terreno empleándose para ello la aplicación ODK Collect (Jordán, 2018a, p. 270). Por último, los datos obtenidos han sido procesados por medio de los programas Filemaker y QGIS.

4 Conviene apuntar que la recogida de material en campo efectuada en el 2001 algo, por otra parte, habitual en la realización de prospecciones arqueológicas, provocó la drástica disminución, cuando no desaparición, de la presencia de artefactos en superficie. Un ejemplo de esta situación pudimos apreciar en el sitio de Portillo Almadieros II, un pequeño sitio emplazado en un lugar estratégico de paso en el que se recogieron 52 restos de sílex en 1991 y en el que en 2017 solo pudimos identificar dos. Más extremo es el caso de Peña XIX, posiblemente otro sitio de pequeña entidad también emplazado en un claro lugar estratégico de paso en el que se recogieron treinta y nueve artefactos en el contexto de las prospecciones de 2001 y en el que en 2017 no se encontró resto alguno. En cualquier caso, como una forma de paliar el problema que supone la recogida previa de material a la calidad del registro, también se han empleado estas piezas para realizar la caracterización material de cada asentamiento, puesto que proporcionan una imagen más completa de estos. 
En general, como se puede apreciar en la figura 3, la prospección intensiva del territorio ha permitido el inventario de 4806 artefactos, de los cuales 632 están realizados en sílex. A través de su concentración espacial (Barton, Bernabeu, Aura, Garcia \& La Roca, 2002, pp. 166, 183; Gomes de Mello, 2001-02, p. 8; Hodder \& Orton, 1990, p. 28; Terrenato, 2001, 365) se han podido identificar al menos veinticuatro sitios de diferente carácter (figs. 4 y 5 ) pero con una cronología prehistórica posiblemente anterior al Bronce, dada la ausencia de elementos claramente vinculados a esta cronología. De entre ellos destaca la presencia de nueve sitios con una cronología homogénea centrada en el Calcolítico (3250-1800 a. C.) ${ }^{5}$ (fig. 6), apreciada en la presencia de útiles con retoque plano (Armendáriz, 1997, p. 26; Cabello, 2005, p. 34; Ortiz, 1990, p. 136; Sesma et al., 2009, p. 134) como en Peña XII (n. ${ }^{\circ}$ 4), Peña XIII (n. ${ }^{\circ}$ 5), o Peña XV (n. ${ }^{\circ}$ 6); elementos líticos característicos como puntas foliáceas (Beguiristáin, 1982, p. 137; Cabello,

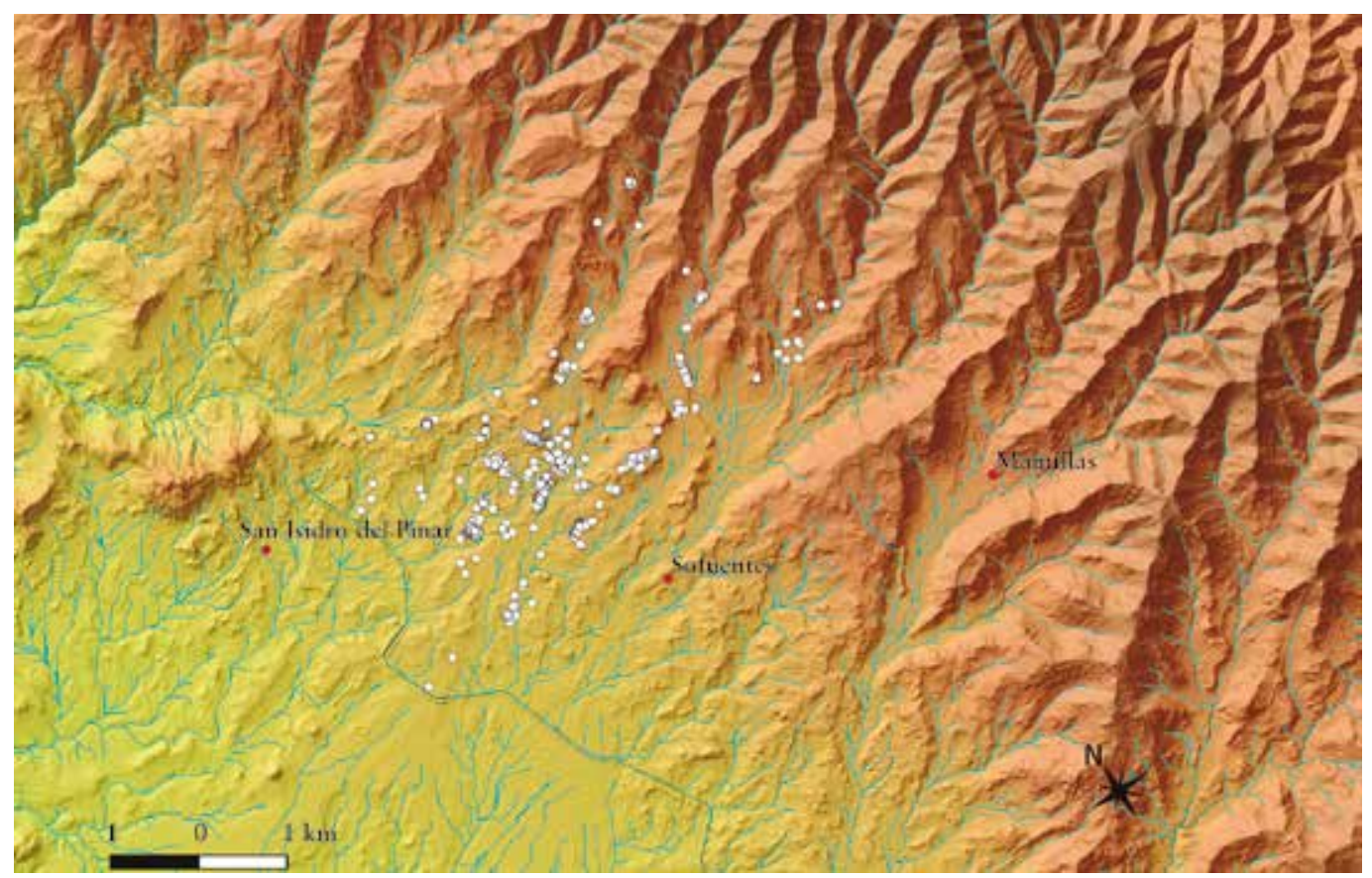

Figura 3. Distribución de artefactos realizados en sílex en el área de prospección.

5 Cantidad que, sin duda, contrasta con los veintidós sitios calcolíticos identificados en las prospecciones del IAN (Peña IV, Peña VI, Peña VII, Peña VIII, Peña IX, Peña X, Peña XI, Peña XII, Peña XIII, Peña XV, Peña XVI, Peña XVII, Peña XIX, Peña XX, Peña XXII, Peña XXIII, Peña XXVI, Peña XXVII, Peña XXX, Zona de Petricos I, Zona de Petricos III y Muga de Peña III). En este sentido la revisión de los materiales recogidos en prospecciones previas y nuestra propia investigación en el campo mostraron que la mayor parte de estas reducciones cronológicas no tenían un fundamento claro avalado por los restos materiales, correspondiendo a sitios de cronología prehistórica, quizá en algunos casos centrados entre el Neolítico y Calcolítico (60001800 a. C.) habida cuenta de la ausencia de restos cerámicos (Peña VI, Peña VII, Peña VIII, Peña XVI, Peña XIX, Peña XX, Peña XXII, Peña XXVI, Peña XXX, Zona de Petricos I y Zona de Petricos III) o entre el Calcolítico y Bronce (3000-1000 a. C.) en otros casos donde se pudieron identificar restos cerámicos indeterminados (i. e. Peña IX) o dientes de hoz (i. e. Peña XVII). 


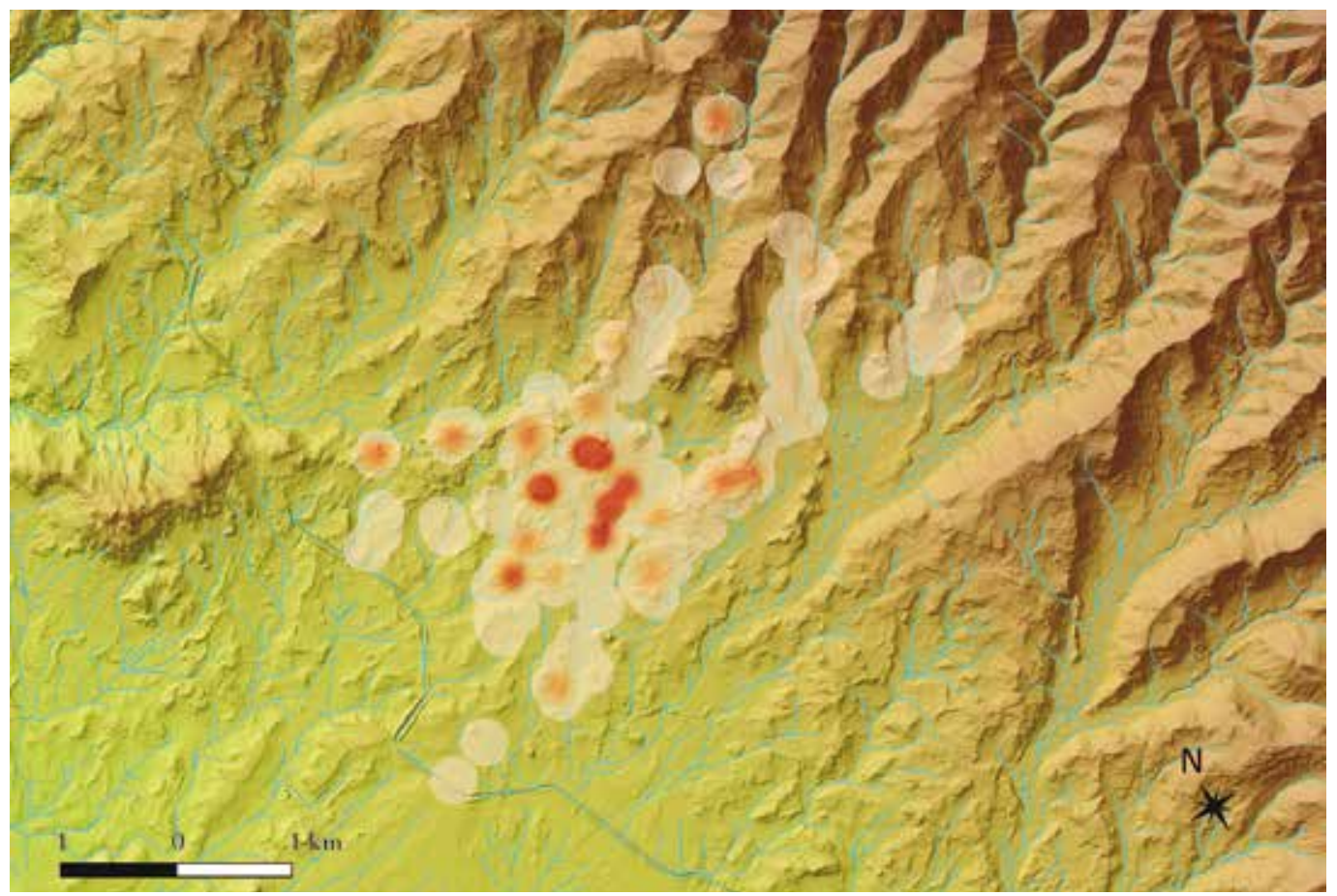

Figura 4. Densidad de concentración de artefactos líticos en la zona prospectada. El análisis se ha realizado a partir de la interpolación Kernel tomando como base un MDT a escala $5 \mathrm{~m}$ y empleando un radio de $200 \mathrm{~m}$.

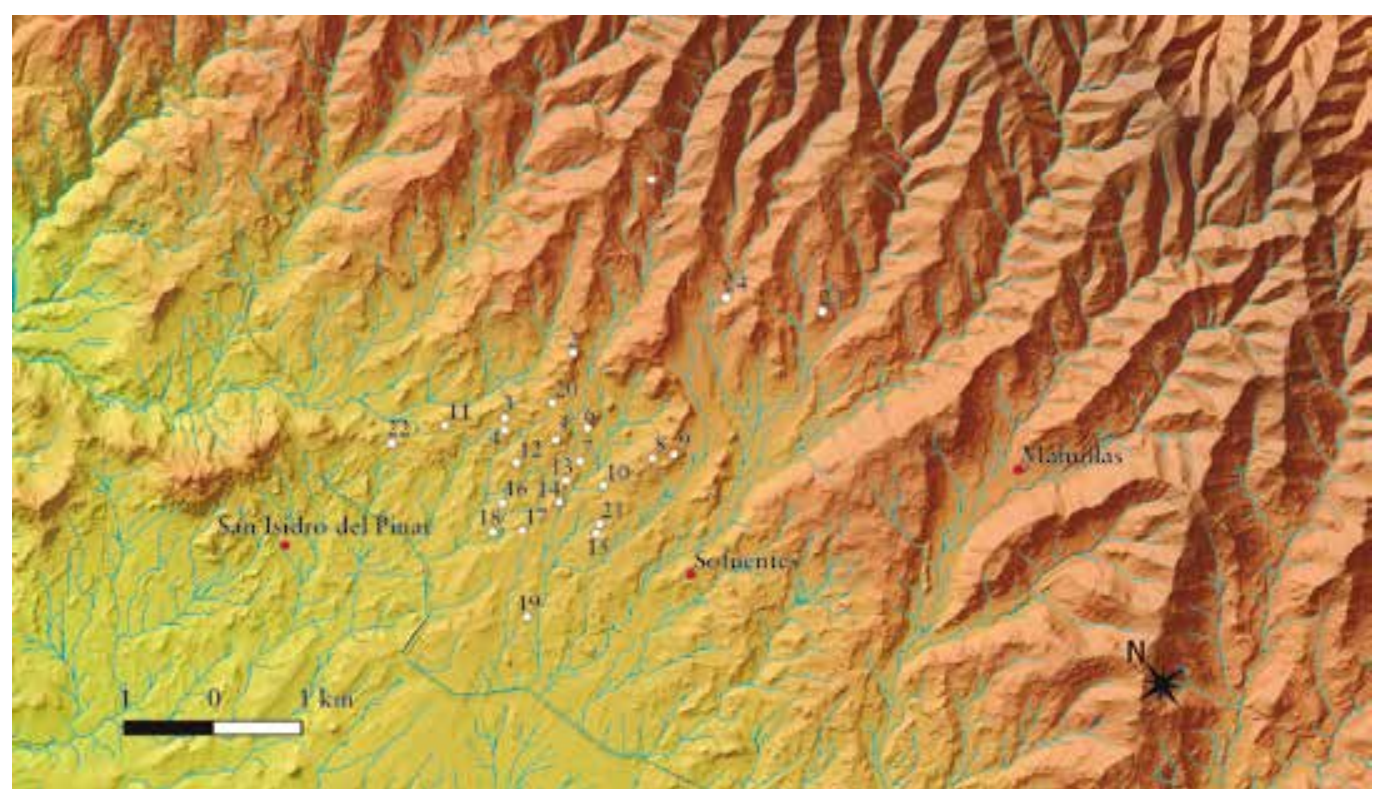

Figura 5. Sitios prehistóricos identificados en la III campaña de prospecciones. 1: Peña IV; 2: Peña XX; 3: Peña XII; 4: Peña XI; 5: Peña XIII; 6: Peña XXVI; 7: Peña XXVII; 8: Zona de Petricos III; 9: Muga Sofuentes III; 10: Peña XXII; 11: Muga de Peña III; 12: Peña X; 13: Peña XVII; 14: Peña XVI; 15: Peña XXXVII; 16: Peña IX; 17: Peña XV; 18: Peña VII; 19: Peña XXIII; 20: Peña XIX; 21: Peña XLI; 22: Portillo Almadieros II; 23: Peña VI; 24: Peña V. 


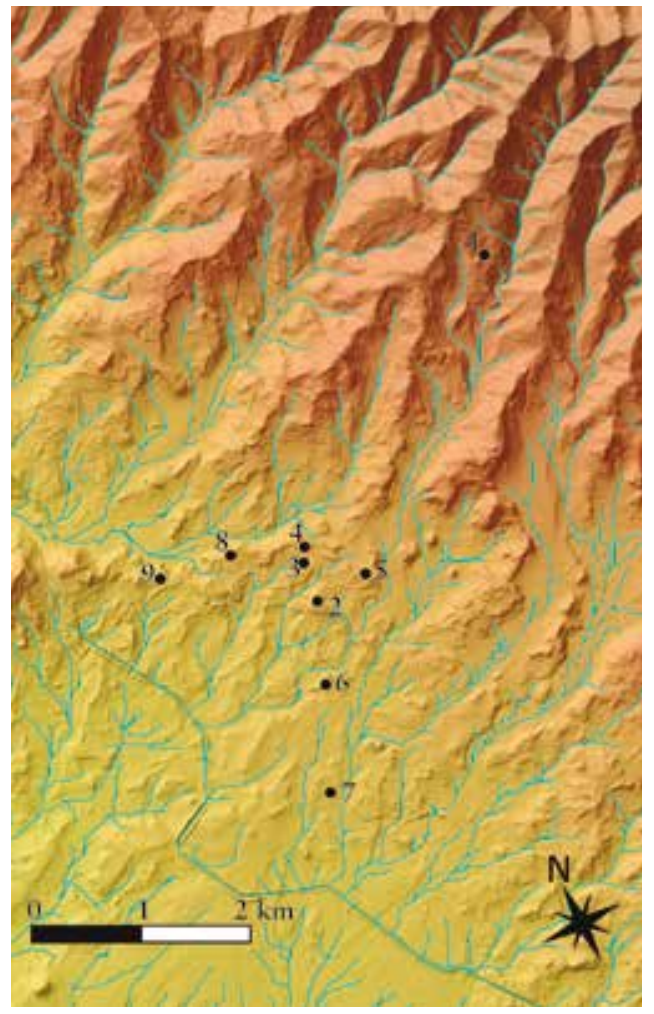

Figura 6. Sitios calcolíticos identificados en la III campaña de prospecciones: 1: Peña IV; 2: Peña X; 3: Peña XI; 4: Peña XII; 5: Peña XIII; 6: Peña XV; 7: Peña XXIII; 8: Muga de Peña III; 9: Portillo Almadieros II.

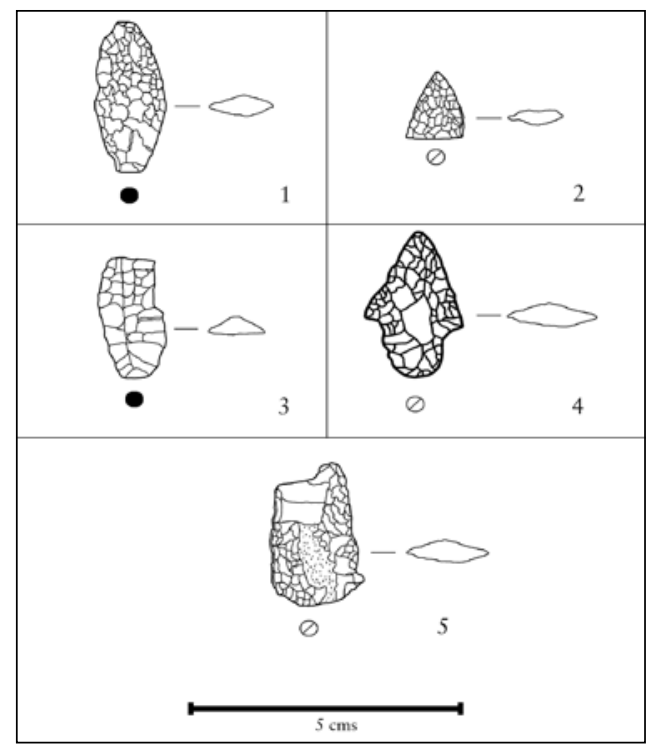

Figura 7. Puntas de flecha procedentes de los sitios del grupo de Peña. 1: Peña XII; 2: Peña XI; 3-4: Peña X; 5: Muga de Peña III.
2005, p. 34; Montes \& Domingo, 2014, p. 410; Ortiz, 1990, p. 136; Ramos et al., 1991, p. 217) aparecidas en Peña X (n. ${ }^{\circ}$ 2), Peña XI (n. ${ }^{\circ}$ 3), Peña XII (n. $\left.{ }^{\circ} 4\right)$ y Muga de Peña III (n. ${ }^{\circ}$ 8) (fig. 7); o la presencia de hachas y/o azuelas pulidas realizadas en ofita en unión a la ausencia de restos cerámicos como en Peña IV (n. ${ }^{\circ}$ 1), Peña XV (n. ${ }^{\circ}$ 7) y Portillo Almadieros II (n. ${ }^{\circ}$ )).

La mayor parte de estos sitios (n. ${ }^{\text {os }} 2-6$ y 8-9) se concentran en un pequeño espacio de poco más de $2 \mathrm{~km}^{2}$, lo cual permite plantear su interpretación como un grupo unitario, habida cuenta que la distancia media existente entre los sitios permanentes de tipo "poblado o aldea» no suele descender de los $8 \mathrm{~km}$ (Cabello, 2005 , p. 31). Este aspecto resalta más al contrastar los datos obtenidos para época calcolítica en esta zona con la de otros espacios prospectados hasta el momento, apreciándose claramente la existencia de dos conjuntos de sitios calcolíticos separados por una distancia de $5 \mathrm{~km}$ (fig. 8).

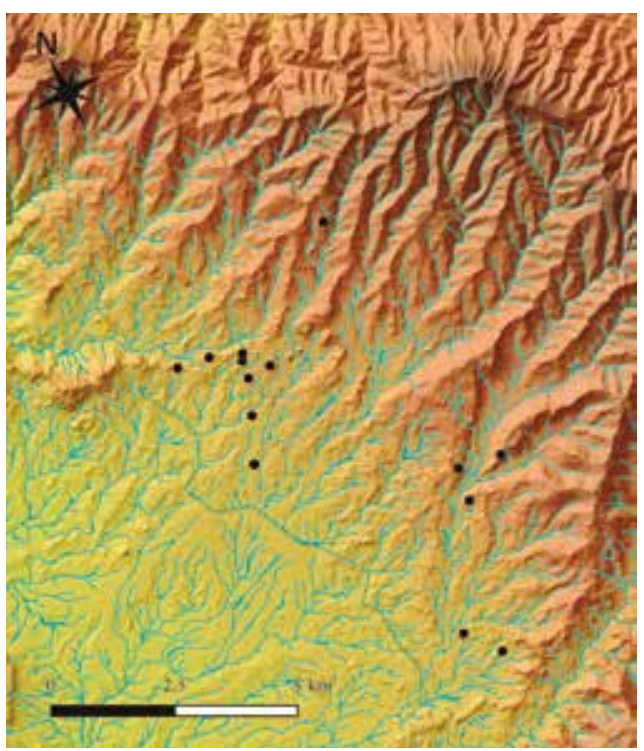

Figura 8. Distribución de sitios calcolíticos conocidos hasta el momento en la zona. 
Por último, los sitios n. ${ }^{\text {os }} 1$ y 7 aparecen claramente distanciados del resto del conjunto aunque, como se verá más adelante, sus peculiaridades intrínsecas quizá permitan interpretarlos como sitios de ocupación temporal. De esta forma tal vez se puedan considerar como reminiscencias de hipotéticas rutas de comunicación de este grupo hacia el norte y el sur.

\section{INTERPRETACIÓN}

\subsection{Aspectos generales}

Pese a que en todo momento se están manejando datos procedentes de prospecciones que por sus características intrínsecas no permiten extraer demasiadas conclusiones y además obligan a actuar con cautela en estas (i.e. Anschuetz et al., 2001; Terrenato, 2004; Witcher, 2006), es posible realizar una primera aproximación a este conjunto de sitios atendiendo a elementos generales como su localización, material o cronología.

En general todos los sitios documentados pueden catalogarse como "yacimientos líticos de superficie o al aire libre» cuyo única coincidencia, más allá de su proximidad y cronología, es la aparición en superficie del hallazgo, no pudiéndose documentar una estratigrafía y, además, con una extensión difícil de definir (i. e. Barandiarán \& Cava, 1981; Beguiristáin, 1982; Cabello, 2005, p. 14) que, en nuestro caso y a modo de aproximación, se ha calculado a través de un mapa de densidades realizado a partir de la interpolación Kernel y empleando un radio de 200 m (fig. 4), metodología empleada con éxito en otros entornos (i.e. Grau et al., 2012).

Centrando la atención en el lugar de emplazamiento de los sitios identificados, conviene precisar que todos se emplazan en las cumbres de pequeñas colinas exceptuando Peña XXIII (n. ${ }^{\circ}$ ), que parece disponerse en una terraza situada en la ladera de una antigua colina muy modificada actualmente, dispuesta a apenas $5 \mathrm{~m}$ sobre un barranco. En general estos datos coinciden con la disposición predominante en época neolíticacalcolítica de ocupación de las alturas y sitios de control (i. e. López Astilleros, 1993, p. 332; Montes \& Domingo, 2014, p. 410) ${ }^{6}$.

Un segundo aspecto a destacar es que la mayor parte de estos sitios aparecen dispuestos a una altura media de unos $521 \mathrm{msnm}$, dentro de la media constatada para los yacimientos al aire libre (Beguiristáin, 1982, p. 108, si bien M. Ramos la rebaja a la franja 382-500 m, Ramos, 2009, p. 67). Así solo el sitio de Peña IV (n. ${ }^{\circ}$ 1) se muestra

6 Sin embargo, estos datos contrastan con la media calculada para los yacimientos al aire libre en el alto valle del Ebro, que plantea que al menos la mitad de ellos se emplazan en la falda de los montes (44,79 \%, vid. Beguiristáin, 1982, p. 79). En cualquier caso este dato debe tomarse con cautela, pues quizá los sitios en alto pueden estar sobrerrepresentados debido a los procesos postdeposicionales que tienden a colmatar por gravedad las áreas más bajas del entorno. 
a un nivel claramente superior $(680 \mathrm{~m})$ posiblemente consecuencia de su emplazamiento en la parte media/alta del barranco de Valdelasviñas (tabla 1). En relación con ello conviene destacar que los sitios aparecen concentrados en la parte media del valle, eligiendo no entrar demasiado en los valles cerrados y siempre sobre colinas no muy grandes, que apenas sobresalen entre los $16-20 \mathrm{~m}$. de media con respecto a los valles que las circundan.

Tabla 1. Relación de sitios de cronología calcolítica incluidos en el grupo de Peña

\begin{tabular}{|c|c|c|c|c|c|c|c|c|c|c|c|}
\hline \multirow[t]{2}{*}{$\mathbf{N}^{\mathbf{o}}$} & \multirow[t]{2}{*}{ Nombre } & \multirow{2}{*}{$\begin{array}{c}\text { Dimen- } \\
\text { siones } \\
\left(\mathbf{m}^{2}\right)\end{array}$} & \multirow{2}{*}{$\begin{array}{l}\text { Loca- } \\
\text { liza- } \\
\text { ción }\end{array}$} & \multirow{2}{*}{$\underset{(\mathbf{m})^{7}}{\text { Altura }}$} & \multirow{2}{*}{$\begin{array}{l}\text { Distancia } \\
\text { a fuente } \\
\text { de agua } \\
\text { (m) }\end{array}$} & \multicolumn{6}{|c|}{ Material } \\
\hline & & & & & & $\begin{array}{l}\text { To- } \\
\text { tal }^{8}\end{array}$ & $\begin{array}{c}\text { Resto } \\
\text { de } \\
\text { talla }\end{array}$ & $\begin{array}{c}\text { Las- } \\
\text { ca }\end{array}$ & $\begin{array}{c}\text { Lámi- } \\
\text { na }\end{array}$ & $\begin{array}{l}\text { Úti- } \\
\text { les }\end{array}$ & $\begin{array}{l}\text { Macro- } \\
\text { lítica }^{10}\end{array}$ \\
\hline 1 & Peña IV & 2343 & Ladera & $681 / 19$ & 213 & 43 & 26 & 11 & 1 & 4 & 1 \\
\hline 2 & Peña X & 10000 & Alto & \begin{tabular}{|l|}
$511 / 25$ \\
\end{tabular} & 153 & 127 & 61 & 27 & 25 & 8 & 6 \\
\hline 3 & Peña XI & 552 & Ladera & $506 / 19$ & 102 & 29 & 16 & 7 & 4 & 2 & - \\
\hline 4 & Peña XII & 6600 & Alto & $518 / 16$ & 145 & 31 & 20 & 3 & 1 & 7 & - \\
\hline 5 & Peña XIII & $6396^{11}$ & Alto & $524 / 19$ & 249 & 220 & 160 & 26 & 22 & 10 & 2 \\
\hline 6 & Peña XV & 8800 & Alto & $486 / 14$ & 146 & 22 & 18 & - & 1 & 1 & 2 \\
\hline 7 & Peña XXIII & 3380 & Ladera & $468 / 5$ & 124 & 33 & 17 & 9 & 4 & 3 & - \\
\hline 8 & $\begin{array}{c}\text { Muga de } \\
\text { Peña III }\end{array}$ & $1231^{12}$ & Alto & $496 / 16$ & 196 & 46 & 32 & 4 & 5 & 4 & 1 \\
\hline 9 & \begin{tabular}{|c|} 
Portillo \\
Almadieros II \\
\end{tabular} & 1256 & Ladera & $500 / 10$ & 200 & 54 & 0 & 50 & 3 & 0 & 1 \\
\hline
\end{tabular}

7 Izquierda: altura sobre nivel del mar. Derecha: altura sobre el nivel del valle.

8 Con la finalidad de obtener una imagen más completa de los sitios que se estudian en el presente trabajo se incluye en el inventario de materiales tanto los que se han inventariado en el año 2017 y que, con muy pocas excepciones, se dejaron en el campo, como los que se recogieron en 2001 y se conservan en el almacén de arqueología del Gobierno de Navarra.

9 Entendiendo como tales las piezas sin forma aparente, de pequeño tamaño, mal conservadas y golpeadas. Por otro lado las lascas, aun cuando también son efectivamente restos de talla, se han individualizado.

10 Elemento lítico de factura no silícea (molinos barquiformes, percutores, hachas, azuelas, etc.).

11 A este respecto, conviene apuntar que la concentración de materiales ha llevado a reducir sensiblemente el área de extensión del sitio desde los $25200 \mathrm{~m}^{2}$ que se planteaba en el IAN (VV. AA., 2001), consecuencia de incluir en la estimación la parcela inferior a la que nos atañe, espacio en el que no solo no se han localizado artefactos en la campaña de 2017 , sino que por su posición posiblemente sea receptor de materiales de arrastre.

12 Esta disposición reduce extraordinariamente el perímetro establecido durante las prospecciones del 2001, en donde se planteó una extensión del yacimiento ocupando la cima de la colina (VV. AA., 2001). 
Un tercer aspecto a considerar de este conjunto de sitios es su relativa cercanía a una fuente de agua (tabla 1), aspecto esencial para cualquier tipo de asentamiento humano (i. e. Chapman, 1991) e igualmente constatado en asentamientos de esta época (Ramos, 2009 , p. 67). En este sentido conviene apuntar que no se han identificado manantiales ni recursos hídricos estables en la zona aunque todos los vecinos propietarios de las tierras consultados coinciden en apuntar la existencia de esta en gran cantidad en el subsuelo. Por esta razón para establecer las distancias se ha atendido a la red secundaria, formada sobre todo por barrancos. A través de ella se puede establecer una distancia media de $160 \mathrm{~m}$ de una potencial fuente de agua, algo por otra parte lógico. Ahora bien, en contraste con la importancia de los recursos hídricos como base para la subsistencia humana, la disposición de los sitios permite intuir que su control no estuvo en la base de su desarrollo. En este sentido si durante el Neolítico parece percibirse un cierto interés por el control del barranco de Pintanés a través de los sitios de Peña XXIII y Peña XXVII, los nuevos sitios que surgen en el Calcolítico tienden a reforzar la presencia y control del área occidental en detrimento de los barrancos más importantes situados a oriente.

Centrando la atención en los materiales identificados conviene subrayar que la manifiesta exigüidad de su composición, apenas medio millar de piezas, impide realizar un acercamiento tipológico pormenorizado con garantías, aspecto incrementado por la pequeña cantidad de útiles identificados (41). Aun así es posible apreciar algún dato general como se observa en la figura 9. De esta forma aunque la mayor parte de los restos encontrados corresponden a restos de talla $(73,8 \%)$, algo habitual en los sitios al aire libre, el mayor peso existente de lascas $(11,3 \%)$ con respecto a láminas $(9 \%)$ responde a unos valores usuales para esta época en la cuenca del Ebro, periodo en el que la técnica de extracción de láminas retrocede en beneficio de la talla en lasca (Cabello, 2005, p. 19; Cava, 1986).

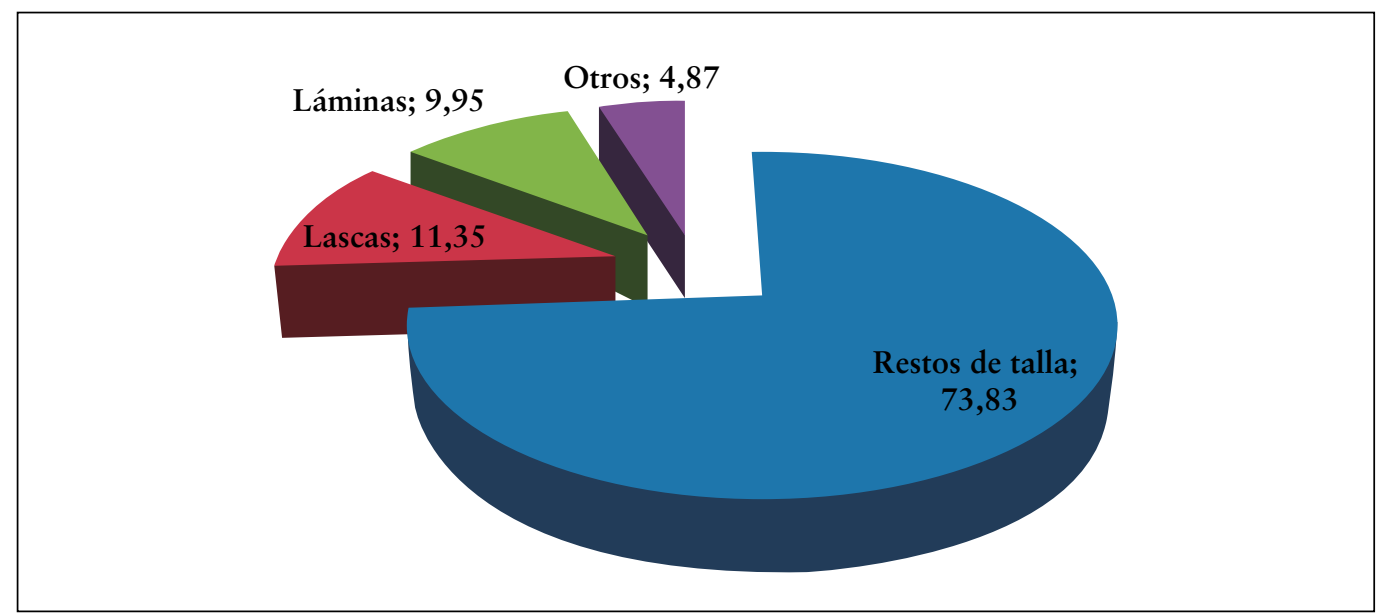

Figura 9. Distribución tipológica de los artefactos realizados en sílex encontrados en la zona de prospección.

Por otro lado si bien los útiles encontrados son escasos cabe destacar la presencia de tipologías como raspadores (fig. 10) y puntas de flecha (fig. 7) como las más frecuentes, en detrimento de otras como cuchillos o punzones que son claramente anecdóticas. En 


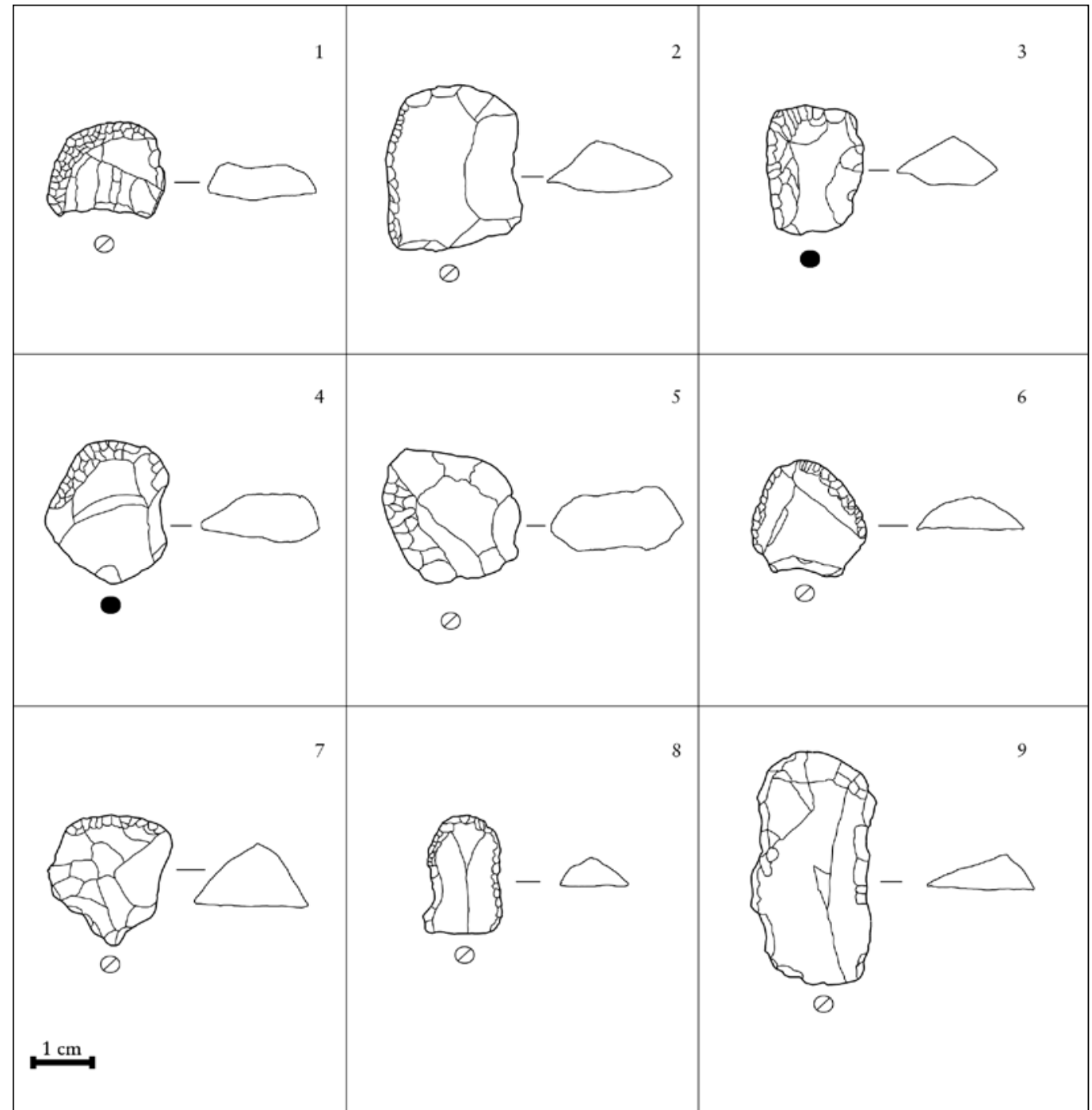

Figura 10. Raspadores procedentes de los sitios del grupo de Peña. 1: Peña IV; 2: Peña X; 3-6: Peña XII; 7: Peña XV; 8-9: Peña XXIII.

este sentido sorprende la ausencia generalizada de cerámica, aunque parece tratarse de una característica común a los sitios calcolíticos conocidos en la zona (Armendáriz \& Irigaray, 1991-92, pp. 224-225; Cabello, 2005, p. 18).

Desde un punto de vista geológico no se han encontrado afloramientos o fuentes de sílex en las cercanías, razón por la que quizá pueda plantearse que su presencia es importada. Así se ha planteado la posibilidad de que proceda del valle del Onsella, lugar donde se ha postulado la presencia de afloramientos de sílex aunque sin concretar (Beguiristáin, 1982, p. 109), o bien de zonas periféricas como el Pirineo axial o los montes calcáreos de Castejón (Cabello, 2005, p. 31). 
Atendiendo a la cantidad de artefactos identificados es posible dividir estos sitios en diferentes grupos (Bernabeu, Aura \& Badal, 1993, p. 218; Cabello, 2005, pp. 30-31) que, quizá, pudieron tener diferente carácter como se puede apreciar en la figura 11 . De esta forma es posible distinguir en relación a la cantidad de artefactos identificados en cada sitio y, en menor medida, a la superficie al menos cuatro grupos distintos: El grupo A, compuesto por sitios en donde se han encontrado 50 o menos artefactos; el grupo B, compuesto por aquellos sitios con una cantidad de artefactos de entre 50 y 100 ; el grupo $\mathrm{C}$ compuesto por aquellos sitios que han proporcionado una cantidad de entre $100 \mathrm{y}$ 200 artefactos; y, por último, el grupo D, compuesto por aquellos sitios que presentan más de 200 artefactos:

Grupo A: n.os 1, 3, 4, 6, 7 y 8

Grupo B: ¿n. ${ }^{\circ}$. 9?

Grupo C: n.․ 2

Grupo D: n. 5

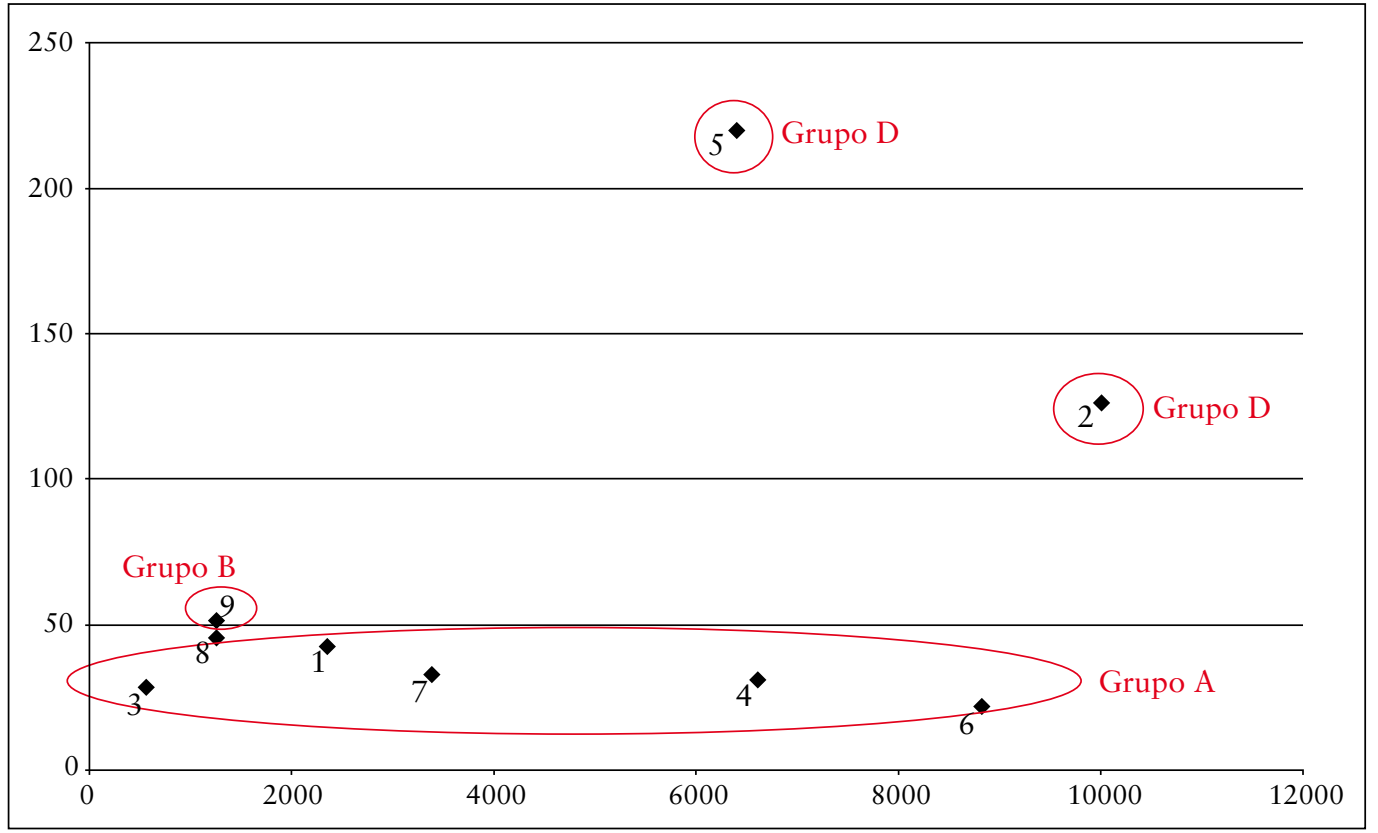

Figura 11. Relación superficie/cantidad de artefactos entre los sitios del grupo de Peña.

Plantear interpretaciones claras de carácter funcional sobre estos grupos es complicado por cuanto que la cantidad de material y, sobre todo, su extensión no siempre es correspondida con la realidad arqueológica que presenta una excavación ${ }^{13}$. En cualquier

13 Por desgracia no es posible realizar una extrapolación directa (ni indirecta) entre la superficie de distribución de material y el tamaño del sitio. Esta situación que permite una cierta aproximación para periodos históricos, en épocas anteriores se muestra extraordinariamente aleatoria. 
caso, como se verá más adelante $(\mathbb{S} 4.2)$ los sitios incluidos en el grupo A, que muestran una pequeña cantidad de artefactos junto a una pequeña superficie de extensión ${ }^{14}$, a modo de hipótesis tal vez puedan identificarse con pequeños sitios de ocupación temporal o estable (Cabello, 2005, p. 31). En el extremo contrario quizá puedan encuadrarse los sitios de los grupos C y D cuya cantidad de artefactos atestiguada es muy grande y viene acompañada por una gran superficie de distribución, lo cual tal vez sea indicativo de una cierta sedentarización aspecto que, como se verá más adelante, quizá pueda confirmarse a través del material conservado. Por último, los sitios incluidos en el grupo B se encuentran en un estado de indefinición aunque no podría descartarse su consideración como sitios continuos de pequeño tamaño. Otra opción podría ser la de categorizarlos como "asentamientos especializados o de uso logístico", como se ha realizado para aquellos caracterizados por poseer menos de 100 elementos en sus recuentos particulares, acompañados por una escasa diversificación tipológico-funcional (Cabello, 2005, p. 31).

De esta forma si se atiende a la división en grupos planteada, la mayor parte de estos sitios (seis) se pueden encuadrar en el grupo A, sobresaliendo solo dos sitios: Peña X (n. ${ }^{\circ}$ 2) y, especialmente, Peña XIII (n. ${ }^{\circ}$ ), tanto por cantidad de artefactos encontrados como por tamaño, sobre los que se centrará la atención a continuación.

\subsection{Principales sitios atestiguados: Peña XIII y Peña X}

Sin duda Peña XIII (n. ${ }^{\circ}$ ) sobresale con diferencia con respecto a todos los demás sitios identificados puesto que es el que ha proporcionado una cantidad mayor de artefactos (220) en una superficie de dispersión relativamente amplia de $6396 \mathrm{~m}^{2}$. Se localiza cerca de la cumbre de un pequeño cerro de $522 \mathrm{~m}$ de altura ocupando una parcela alargada orientada en sentido O-E y a 249 m del curso de agua más cercano. Pese a tratarse de uno de los principales sitios conocidos conviene resaltar que su control visual sobre el territorio es muy escaso, aunque parece claramente orientado hacia el control del barranco de Pintanés, tanto al norte donde se tiene una gran visibilidad de Peña IV (n. $\left.{ }^{\circ} 1\right)$ como al sur, donde tiene un buen contacto visual con Peña XV (n. ${ }^{\circ}$ 6). Sin embargo, en contraposición, la visibilidad de la mayor parte de los sitios calcolíticos, situados de forma predominante al oeste, es escasa (fig. 12).

14 En relación con ello resulta sorprendente la amplia superficie de distribución que se aprecia en los sitios de Peña XII (n. ${ }^{\circ}$ 4) y Peña XV (n. ${ }^{\circ}$ ), pese al escaso número de materiales identificados. Con respecto a ello conviene advertir que ninguno de ellos pudo ser identificado durante la III campaña de prospecciones, bien porque las condiciones del campo impedían la visibilidad del terreno (caso de Peña XII) o bien porque apenas se encontró material en el sitio (caso de Peña XV). En general la prospección con georreferenciación de material en el resto de sitios ha conllevado la reducción del área de dispersión de cada uno en ocasiones en más de un 80 \% de la superficie como puede ejemplificar Peña XIII (n. ${ }^{\circ}$ 5) al que se atribuyó una superficie de $25200 \mathrm{~m}^{2}$ que se ha reducido a $6396 \mathrm{~m}^{2}$, por lo que siguiendo esa misma pauta es muy probable que la superficie de distribución de material de estos sitios en realidad sea mucho menor. 


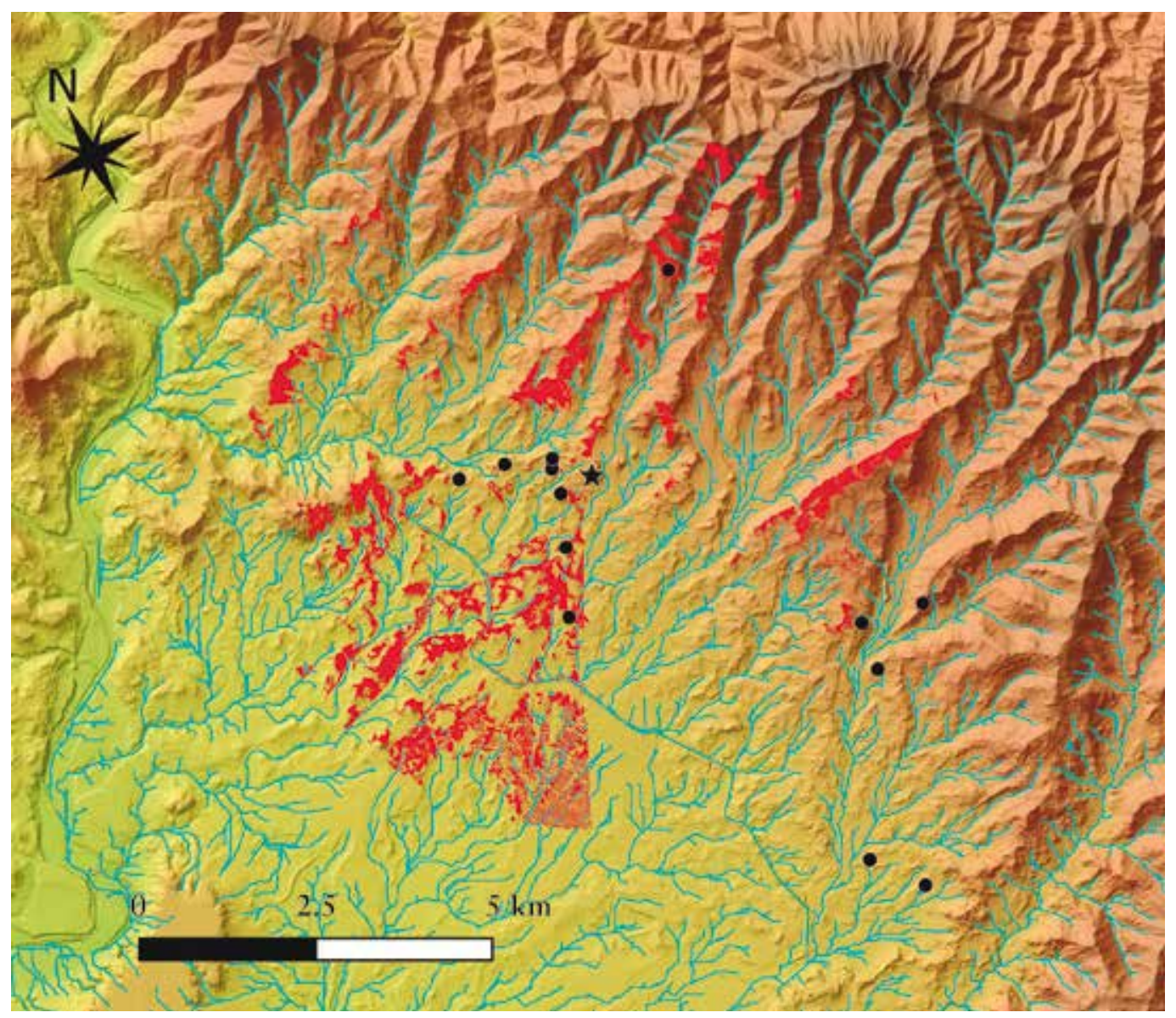

Figura 12. Cuenca visual de Peña XIII. Estudio realizado sobre un MDT 5 con un radio de $5 \mathrm{~km}$ y una altura de observador de $1,6 \mathrm{~m}$ y de objetivo de $0 \mathrm{~m}$.

En el sitio se han inventariado 220 restos de sílex, en su mayor parte correspondientes a restos de talla (152-69 \%), siendo todos ellos del tipo evaporítico. El material identificado se puede vincular, con prudencia, a diversas actividades. Este es el caso de un pedúnculo de una punta de flecha posiblemente relacionado con la caza. Además la presencia de un raspador (fig. 10.6) y hasta cuatro punzones permiten apuntar a diversos elementos de procesamiento de la piel y, dentro de la faceta industrial que igual desarrolló este grupo humano, también cabe destacar la presencia de un núcleo y un percutor de ofita que, sumado a la importante cantidad de restos de talla, permite considerar la realización de este tipo de actividades. En otro contexto vivencial el hallazgo de un molino barquiforme y, quizá, de un cuchillo, permite apuntar al procesado de alimentos.

Todos estos elementos (cantidad de artefactos encontrados, la realización de diferentes actividades y la presencia del molino) tal vez puedan estar indicando la existencia de un núcleo de habitación permanente aunque este punto solo podrá ser confirmado por medio de la realización de excavaciones arqueológicas. Cronológicamente la presencia 
entre los materiales de un segmento de círculo con retoque a doble bisel permite situar el inicio de este sitio en época neolítica perdurando durante el Calcolítico.

A escasos $500 \mathrm{~m}$ al SO de Peña XIII (n..$^{\circ}$ ) se emplaza Peña X (n..$^{\circ}$ 12), también ubicado en la parte alta de un amplio cerro no muy elevado (unos $512 \mathrm{~m}$ ) y a unos $120 \mathrm{~m}$ de distancia del principal recurso de agua. Aunque se encuentra muy cerca de Peña XIII (n..$^{\circ}$ ) a diferencia de él muestra un excepcional control del territorio, pudiéndose ver todos los sitios incluidos en el grupo de Peña (fig. 13).

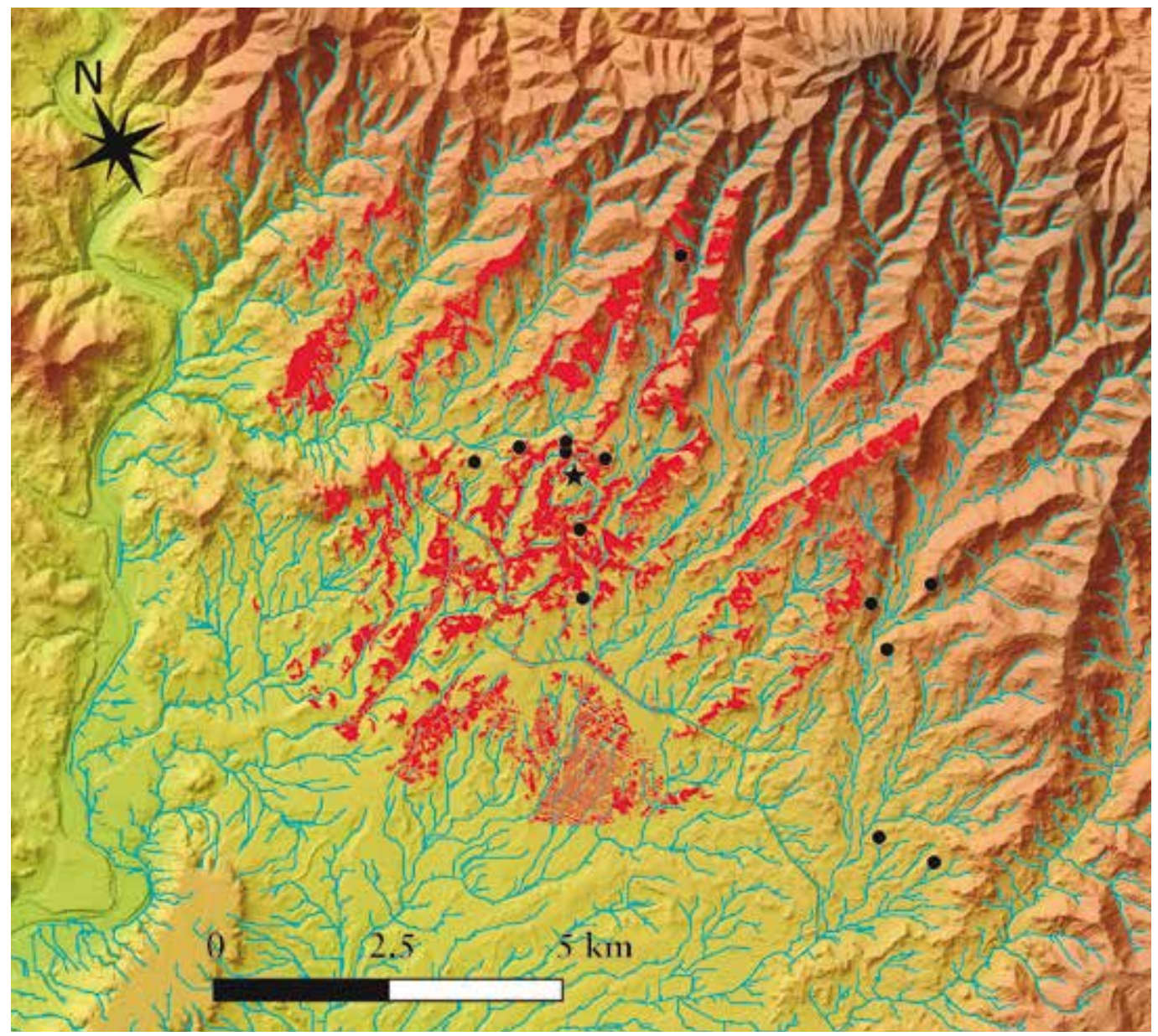

Figura 13. Cuenca visual de Peña X. Estudio realizado sobre un MDT 5 con un radio de $5 \mathrm{~km}$ y una altura de observador de $1,6 \mathrm{~m}$ y de objetivo de $0 \mathrm{~m}$.

En total se han inventariado 130 artefactos casi todos realizados en sílex evaporítico, posiblemente del valle del Ebro, con excepción de un par de piezas realizadas en sílex negro. En contraste con Peña XIII los restos de talla identificados son menos numerosos (48 \%) aunque paradójicamente se ha localizado una gran cantidad de percutores (5), retocadores y un núcleo. 
En general cabe destacar la presencia en el conjunto de dos puntas de flecha (fig. 7.34), claramente relacionadas con la caza, así como de un raspador (fig. 10.2) y un punzón, vinculables al procesamiento posterior de la pieza. También se ha identificado una pequeña hachita pulida de ofita alóctona que por su tamaño debió estar destinada a las labores agrícolas y un cuchillo.

La datación de este sitio es claramente calcolítica, aunque la presencia del hachita pulimentada quizá permita llevarla hasta el Bronce. Sin embargo la ausencia de elementos cerámicos en el registro aconsejan no ampliar tanto esta cronología.

De esta forma, en conclusión, el grupo de Peña muestra dos sitios caracterizados por la gran cantidad de artefactos pero con unas condiciones de emplazamiento, control y composición muy distintas. Peña XIII (n. $\left.{ }^{\circ} 5\right)$ constituye la evolución de un sitio de temprana cronología y, por lo tanto, su localización está condicionada por las necesidades existentes en época neolítica que quizá, a modo de hipótesis, y siguiendo el ejemplo de otros grupos neolíticos cercanos pudo orientarse hacia el control de las tierras meridionales (Jordán et al., 2021). Sin duda esta motivación, que llevó a una localización válida para el momento inicial, evolucionó en un deficitario control del territorio en época calcolítica, lo cual quizá causó el surgimiento de otros sitios más «aptos», como puede Peña X (n. $\left.{ }^{\circ} 2\right)$. En este sentido para el establecimiento de Peña X (n. ${ }^{\circ}$ 2) se escogió un lugar privilegiado, como muestra el completo control de los sitios calcolíticos que se realiza desde allí.

Ahora bien, pese a esta singular importancia que parece adquirir Peña X no deja de sorprender el diferente escaparate de útiles encontrados en uno y otro yacimiento así como la importante diferencia numérica de artefactos existente entre uno y otro. En este sentido no puede olvidarse que el registro procedente de Peña XIII tiene que estar influido por la presencia de útiles neolíticos si bien, por desgracia, con los datos actuales y dada la amplia vida de las tipologías líticas no sea posible perfilar las características de uno y otro periodo. Sin duda esta situación constituye un reflejo claro de las limitaciones que el registro de superficie adquiere para el caso de los sitios con amplia cronología, no pudiéndose avanzar más en la relación que ambos sitios desarrollarían entre ellos.

\subsection{Asentamientos menores: Peña IV, Peña XI, Peña XII, Peña XV, Peña XXIII y Muga de Peña III. ¿Portillo Almadieros II?}

Centrando la atención en el grupo A, sin duda el más numeroso, la poca cantidad de artefactos inventariados unida a su pequeña superficie invita a considerar, con prudencia, que se tratan de sitios de muy pequeña entidad. Su caracterización es muy complicada planteándose para ellos diferentes posibilidades interpretativas, normalmente dentro de una ocupación temporal. En este sentido cabe resaltar que se ha establecido como un elemento indicativo de la movilidad de los grupos la profusión de asentamientos de tamaño inferior a $2000 \mathrm{~m}^{2}$ (López Astilleros, 1993, pp. 333-334), como aquí parece suceder.

En general este tipo de sitios se han visto como «centros complementarios» de los principales (Marcos \& Díez, 2009, p. 780) en atención a su ubicación en lugares estratégicos vinculándolos con labores como la recolección, pastoreo, caza, pesca o abastecimiento 
de materias primas. Otra opción más abierta es la de considerarles una razón de ser completamente aleatoria, asociada a procesos de carácter estacional (Cabello, 2005, p. 31), aunque nuevamente dependientes de asentamientos «multifuncionales» próximos. Por último, un tercer elemento interpretativo planteado es el de interpretarlos como un reflejo de una sociedad cazadora-recolectora (Armendáriz \& Irigaray, 1991-92, p. 237), que en este entorno cronológico podría determinar una funcionalidad ganadera, en el que estarían mostrando la movilidad de un grupo en un territorio determinado en el curso de un año o un ciclo (Butzer, 2007, pp. 279-282; Renfrew \& Bahn, 2013, pp. 196-197).

En el caso del grupo de Peña la posible identificación de los sitios n. ${ }^{\text {os }} 2$ y 5 como estables (vid. $\mathbb{S} 4.2$ ) desaconseja realizar una interpretación basada en una base de subsistencia ganadera. Además este punto se ve reforzado por la presencia de dientes de hoz y molinos de mano en algunos sitios ( $\mathrm{n} .^{\text {os }} 4,5$ y 6) lo cual invita a considerar, con prudencia, la existencia de una base agrícola incipiente.

En general de los seis sitios que integran el grupo A, Peña IV $\left(n .^{\circ} 1\right)$ y Peña XXIII (n. ${ }^{\circ}$ ) no muestran rasgos definitorios en el material conservado, razón por la cual no se pueden vincular con ninguna actividad concreta debiendo reducirlos por el momento, y con prudencia, a simples vestigios de paso, lo cual podría explicar su mayor alejamiento con respecto al núcleo principal del grupo.

Frente a esta situación resultan interesantes los casos de Muga de Peña III (n. ${ }^{\circ}$ 8) y Peña XV (n. ${ }^{\circ}$ 6). Ambos sitios tienen en común un origen cronológico en el Neolítico por lo que su trayectoria diacrónica es más amplia, si bien en el Calcolítico quizá no tienen tanto peso como Peña XIII (n. $\left.{ }^{\circ} 5\right)$. Sin duda entre los dos resalta Peña XV por su extraordinario control del territorio, aspecto que viene acompañado por la presencia entre el utillaje recuperado de raspadores (fig. 10.7), molinos y hachas, todo lo cual quizá esté reflejando una cierta sedentarización en este sitio. En este sentido, a modo de hipótesis y con cautela, quizá podrían tratarse de pequeños enclaves de ocupación continua, especialmente en el caso de Peña XV, reminiscencias de un periodo anterior.

Por otro lado, la cercanía existente entre Peña XII (n. ${ }^{\circ}$ 3) y Peña XI (n.o 4), separados por apenas $70 \mathrm{~m}$., invita a centrar, siquiera brevemente, la atención en ellos. La cantidad de material inventariado, 29 y 31 artefactos respectivamente, es prácticamente similar en ambos sitios aunque, por el momento, la calidad y variedad de este parece centrarse en Peña XII (n. ${ }^{\circ} 3$ ) en donde, además de los habituales restos de talla, lascas y láminas, se ha recuperado un diente de hoz (fig. 14), una raedera y tres raspadores (fig. 10.3-5). Completando esta importancia del material recuperado se puede señalar que su posición en altura permite un control del territorio mucho más amplio. Por el

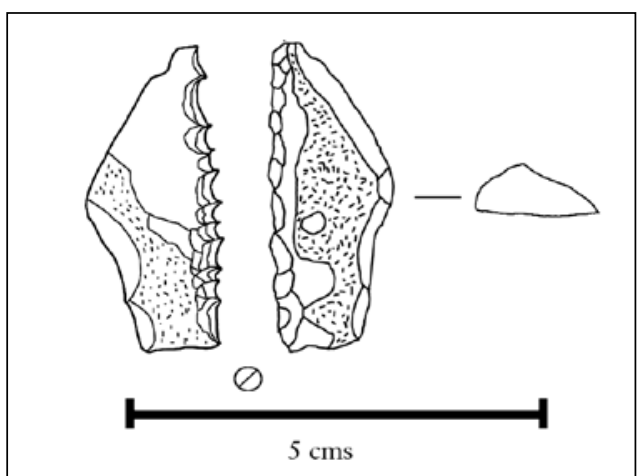

Figura 14. Diente de hoz identificado en Peña XII. 
contrario la posición más baja en la ladera de la misma colina de Peña XI (n. ${ }^{\circ}$ 4) enfoca su zona de control visual hacia el sur. De esta forma, la suma de todos estos datos invita a plantear, con prudencia, que Peña XI (n. $\left.{ }^{\circ} 4\right)$ quizá sea una ampliación de Peña XII (n. $\left.{ }^{\circ} 3\right)$. En este sentido tal vez no se traten de dos sitios de pequeño tamaño sino de un único espacio ocupacional de mayor entidad y quizá de carácter continuo como muestra la presencia de un diente de hoz entre los artefactos recuperados.

Un caso aparte lo constituye el sitio de Portillo Almadieros II (n. ${ }^{\circ}$ ). Estrictamente los 54 artefactos inventariados permiten incluirlo dentro del grupo B, como se ha dicho con anterioridad, aunque sea en su límite inferior. En este conjunto se suelen caracterizar sitios que se interpretan como lugares especializados de funcionalidad diversa (Cabello, 2005, p. 31; Sesma et al., 2009, p. 149). Sin embargo la ausencia de elementos definitorios entre los artefactos localizados en Portillo Almadieros II, compuestos en su mayor parte por restos de talla (lascas y láminas), invitan a considerarlo como un lugar temporal similar a Peña IV o Peña XXIII.

De esta forma, en conclusión, del conjunto de siete sitios que componen los grupos A y B es posible plantear como hipótesis de trabajo que prácticamente todos menos los más alejados quizá pudieron ser asentamientos estables/permanentes de pequeño tamaño, como mostrarían tanto la capacidad de control visual del territorio $\left(\mathrm{n}^{\circ}{ }^{\circ} 3\right)$, su temprana cronología (n. ${ }^{\text {ss }} 6$ y 8 ) o su material (n. ${ }^{\text {ss }} 3,5$ y 6). Para los restantes (n. ${ }^{\text {os }} 1,7$ y 9) por el momento no hay elementos que permitan apuntar a un posible uso estable del sitio. En relación con ello, para finalizar, cabe plantearse si su presencia puede estar fosilizando antiguas redes de comunicación, aspecto que se verá a continuación.

\subsection{Hacia una hipótesis de ocupación del territorio}

La presencia de tantos sitios aparentemente independientes en un pequeño espacio de territorio y con tantas peculiaridades como se han visto necesariamente conduce a plantear una ocupación del territorio basada en el cruce de diferentes estrategias como son la multilocalidad (cfr. Ember \& Ember, 1972), temporalidad (Armendáriz, 1997, p. 30; López Astilleros, 1993, p. 333; Sesma et al., 2009, p. 149) o el movimiento/expansión del sitio (Walker, Hamilton \& Groth, 2014), que no consideramos que sean excluyentes.

Aunque es difícil de comprobar por tratarse de un registro superficial, la construcción de estas relaciones se muestra especialmente interesante para obtener una panorámica completa del uso del paisaje en esta época. En nuestra opinión una forma de resolver, parcialmente pues no hay que olvidar que en todo momento se manejan datos procedentes de prospección, la relación de los asentamientos quizá resida en el cruce de diversos datos, como son las relaciones de antero-posterioridad claras ${ }^{15}$, el tamaño/número de

15 Parece lícito pensar que los sitios que muestren elementos de cronología neolítica necesariamente componen la malla (o parte de ella) desde la que se desarrollaron los restantes sitios en un momento posterior. 
piezas $^{16}$, el tipo de material hallado ${ }^{17}$, la distancia entre los sitios ${ }^{18}$ y la capacidad de control del territorio ${ }^{19}$.

Ello permite plantear, con prudencia, un modelo de poblamiento mixto estable/temporal caracterizado por posibles espacios habitacionales que jerarquizan el territorio y desde el que se despliegan las diferentes estrategias subsistenciales a otras áreas de captación (Marcos \& Díez, 2009, p. 780).

Atendiendo a estos elementos, los datos conservados hasta el momento permiten plantear con prudencia que, de la trama inicial que se estableció en el Neolítico, los sitios n. ${ }^{\text {os }} 5,7$ y $8^{20}$ se emplearon como base sobre la que se desarrolló la ocupación calcolítica (fig. 15) y bajo cuyo influjo se interpreta la ocupación de este espacio en este periodo.

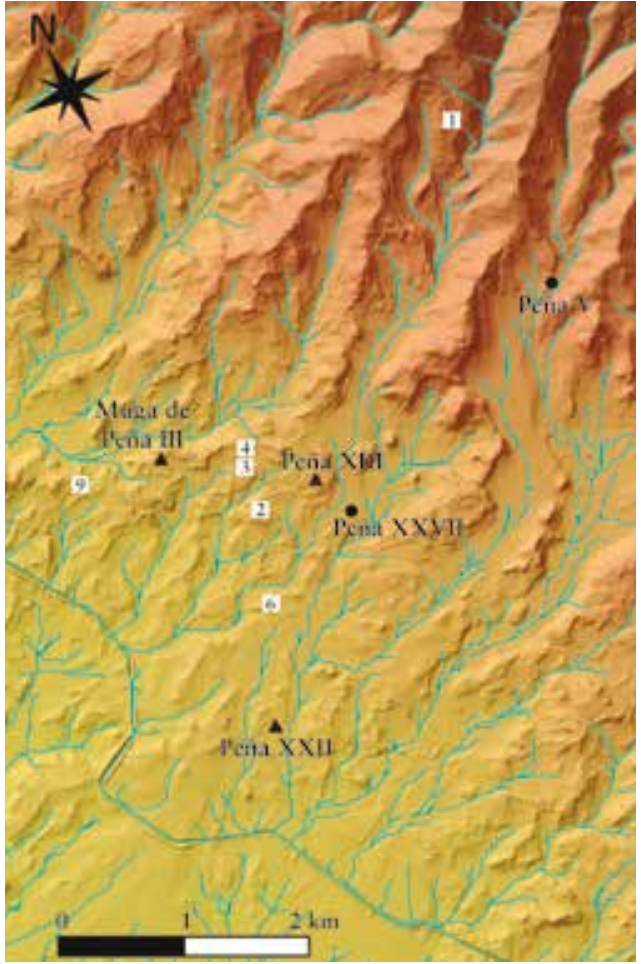

Figura 15. Relación entre la ocupación neolítica de la zona y su evolución en el Calcolítico. Círculo: Sitio neolítico; triángulo: Sitio neolítico con pervivencia en Calcolítico; cuadrado: sitio calcolítico.

16 Las excavaciones en poblados calcolíticos estables en la zona han deparado un número de piezas de sílex que oscilan entre las 173 del poblado de Aspra, incluyendo el material del Bronce (Unanua \& Erce, 2014, p. 92) hasta las siete de San Pelayo IV, incluyendo el material del Bronce (Sesma et al., 2014, p. 142), en cualquier caso no demasiado elevado.

17 Aun cuando su origen necesariamente obliga a manejarlo con cautela, quizá se pueda considerar que la presencia de dientes de hoz, cerámica y molinos, juntos o por separado, permite intuir un cierto grado de sedentarismo.

18 En este sentido, la ocupación neolítica de la zona permite establecer una distancia mínima entre sitios de $500 \mathrm{~m}$, lo cual a su vez facilita establecer un área de explotación de la tierra ideal de 250 ha, suficiente para el mantenimiento de una pequeña población (Lamprecht, 1990). En este sentido, a modo de hipótesis, la existencia de una distancia inferior a la mitad de este parámetro entre un sitio y otro bien podría estar indicando una relación entre ambos, especialmente cuando esta distancia es muy reducida como, por ejemplo, los $70 \mathrm{~m}$ que separan los sitios n. ${ }^{\text {os }} 3$ y 4 .

19 Parece lógico plantear que si los sitios identificados pertenecen a una misma comunidad estos debieron tener un mínimo control visual unos de otros. La existencia de esta visibilidad quizá permita establecer una relación de coexistencia entre ambos sitios, mientras que la falta de visibilidad podría conducir a una relación de antero-posterioridad.

20 La presencia de un hacha de fibrolita de pequeño tamaño en Peña XXIII permiten retrotraerlo al Neolítico pleno (Armendáriz \& Irigaray, 1991-92, p. 224), mientras que los segmentos de círculo en Muga de Peña III y Peña XIII invitan a considerar un origen anterior, quizá en el Neolítico inicial. 
Como se ha dicho con anterioridad, de entre todos los sitios destacan los de Peña X y Peña XIII, que podrían considerarse los principales establecimientos de la zona. Entorno a ellos y en un espacio no superior a los $2 \mathrm{~km}$ se localizan la mayor parte de los sitios relacionados con estos enclaves. Sin embargo, tan importante como la presencia de sitios es la ausencia de estos y en este sentido cabe destacar la práctica ausencia de sitios conocidos, por el momento, a occidente y oriente de este grupo. Esta situación es especialmente sorprendente en la parte oriental, un espacio en el que el grupo calcolítico de Peña muestra un especial interés por tener controlado visualmente, como muestra la creación de Peña X (fig. 13). La explicación a este comportamiento quizá pueda residir en la presencia de un segundo Grupo calcolítico que se está empezando a definir en las últimas campañas de prospecciones al SE del término municipal de Sos del Rey Católico (Zaragoza) y que se emplaza a $5 \mathrm{~km}$ de Peña X y Peña XIII. De esta forma la ausencia de sitios entre ambos núcleos quizá esté reflejando una suerte de espacio limítrofe de uso limitado.

Por otro lado, el contraste entre el control visual sobre el territorio que establece Peña X con respecto a Peña XIII (fig. 16) permite realizar, con prudencia, un acercamiento de

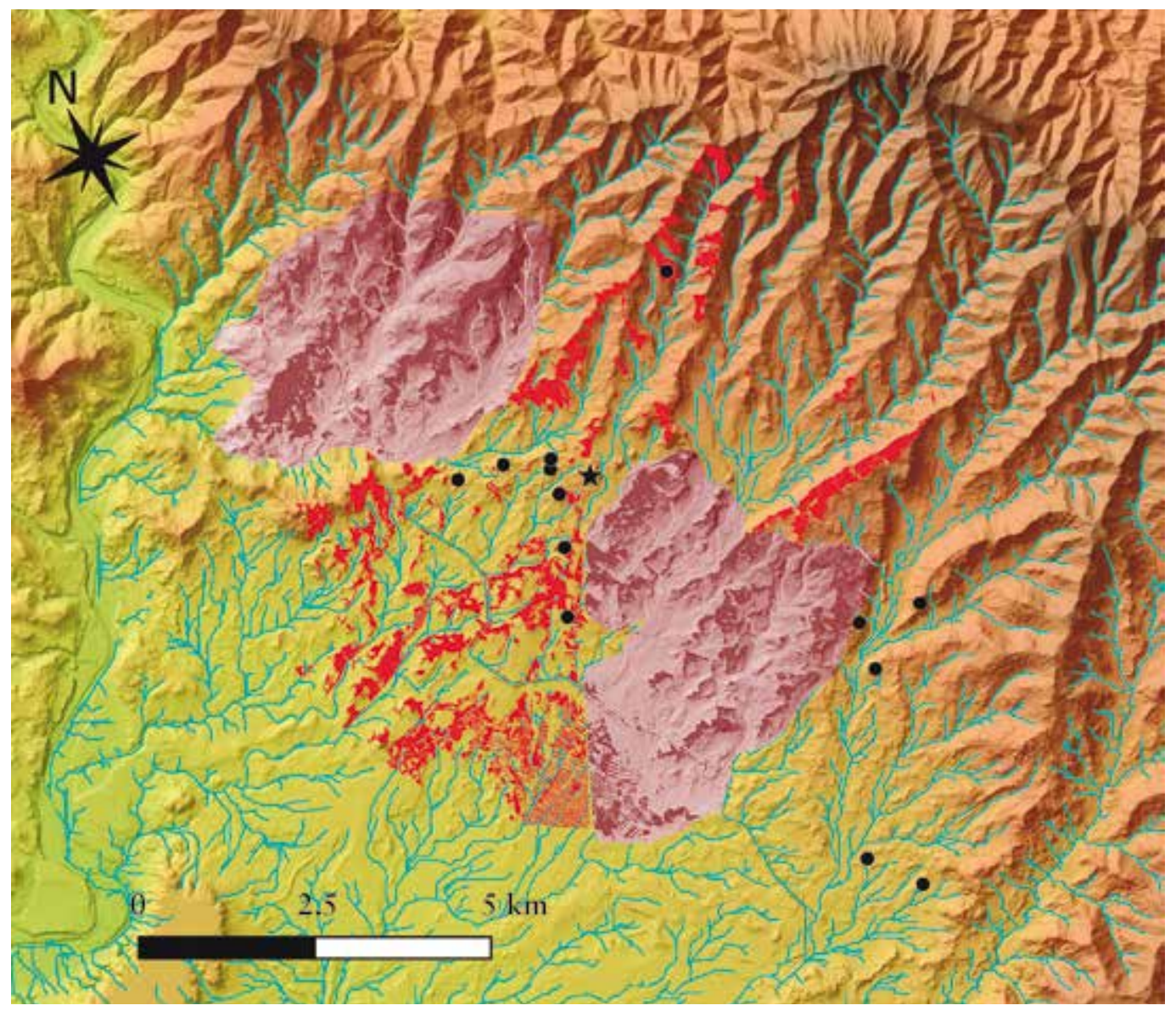

Figura 16. Ampliación del control visual del territorio en el Calcolítico, con base en los dos principales sitios atestiguados (Peña XIII y Peña X). 
primera mano a la identificación de los nuevos intereses que surgen en la sociedad calcolítica y que aparecen complementados por la red de comunicaciones hacia cuatro ejes de interés. En este sentido posiblemente la disposición de asentamientos temporales termina de mostrar la estructuración del territorio para esta época, reflejando las vías de comunicación que lo recorrieron y permitiendo a través de ellas aprehender los principales intereses de este grupo ${ }^{21}$.

Así, como se verá a continuación, además del control visual de la parte oriental del territorio limítrofe con el siguiente grupo calcolítico que se ha comentado con anterioridad, puede apreciarse la búsqueda del acceso a las tierras llanas de los barrancos de Pintanés y Valdelasviñas; el control de la ruta a las fuentes de cobre; y, por último, el control de los pasos hacia el oeste (fig. 17). En este sentido la posible estabilidad de algunos de estos pequeños asentamientos (Peña XI, Muga de Peña III y Peña XV) invitan a considerar con solidez la presencia de estas rutas de comunicación.

Centrando la atención en el primer punto cabe recordar, como se ha dicho con anterioridad, que la creación de Peña X mostraba el interés que tenía el grupo de Peña por el control visual de

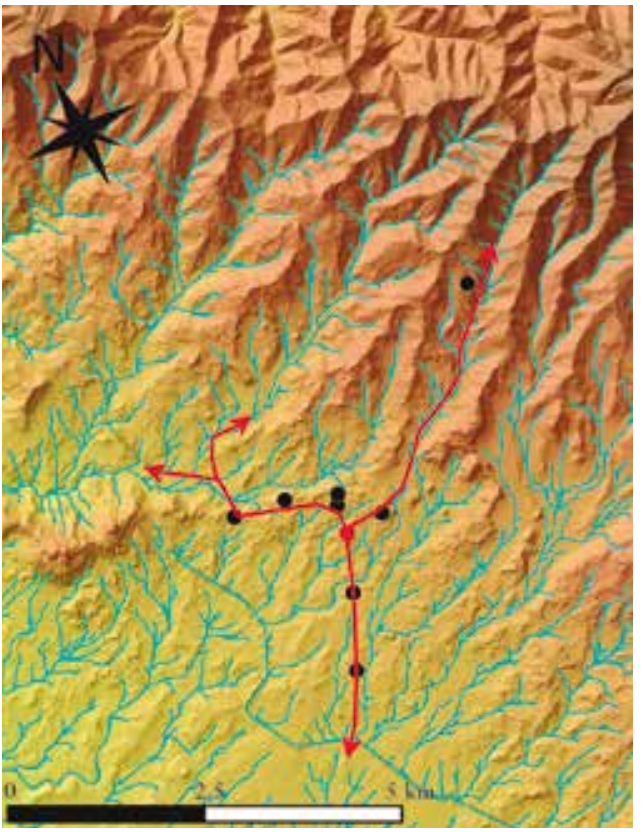

Figura 17. Hipótesis de uso del territorio del grupo de Peña. las tierras llanas situadas al SE. Esta atención se ve confirmada por la creación de Peña XV y el mantenimiento de Peña XXIII, en clara dirección hacia estas tierras llanas. Ahora bien, en relación con ello resulta chocante la ausencia de proyección hacia el sur en donde Peña XXIII (n. ${ }^{\circ}$ 7) quizá pueda atestiguar una suerte de zona de paso, aunque se desconoce su destino. En relación con ello la presencia aislada de un pequeño fragmento de lámina retocada y de un resto de talla quizá podría conducir, a modo de hipótesis, hacia el sitio meridional, de cronología indefinida calcolítica/bronce, de La Torre II (Cáseda), un posible dolmen en avanzado estado de ruina, aunque no deja de ser una teoría.

21 Así, si un sitio puede crearse por la repetición de prácticas en el espacio, no descartamos que la aparición de los sitios temporales fueran consecuencia de la repetición del paso por un mismo lugar de tal forma que tanto ellos como los hallazgos aislados y sin conexión con yacimientos grandes aparecerán con una mayor asiduidad en el entorno de una ruta, comparado con otras zonas donde no pase una vía (Rizvi, 2013, p. 316; Van Lanen \& Pierik, 2017, p. 9). 
Por otro lado, hacia el norte el sitio temporal de Peña IV, situado en la parte superior del barranco de Valdelasviñas, resulta muy interesante. Su emplazamiento en un extremo de la zona del grupo de Peña sin duda no es casual y, en este sentido, necesariamente debe guardar relación con una conexión directa con el norte de la sierra de Peña. Esta ruta ya debió existir en el Neolítico, como muestra la presencia del sitio de Peña V, aunque situado al norte de la Val de la Espina. En este sentido el cambio de valle está reflejando la búsqueda de intereses distintos, quizá relacionables con el acceso a fuentes de cobre, si bien su emplazamiento no está relacionado con el trazado de la ruta óptima para llegar desde los sitios de Peña X (n. $\left.{ }^{\circ} 12\right)$ y Peña XIII (n. ${ }^{\circ}$ ) al afloramiento de cobre en bruto más cercano conocido, junto al sitio de la Sarda al norte de la sierra ${ }^{22}$, aunque se sitúe en el trazado más corto entre ambos puntos.

Por último, hacia el oeste el mantenimiento de Muga de Peña III y la creación de Peña XI y Peña XII parecen reforzar esta orientación, que quizá pueda verse confirmada por la creación de Portillo Almadieros II en un excelente lugar de paso hacia la Val de la Cañada, aunque sorprende la ausencia de un control visual claro de este espacio y de las tierras occidentales. En este sentido es tentador vincular esta orientación con la búsqueda de un camino hacia el río Aragón, situado a $6 \mathrm{~km}$ de Peña X, para aprovechar los recursos que ofrece. Sin embargo, aun sin descartarlo, conviene apuntar que solo se han identificado dos sitios calcolíticos al oeste de este Grupo: Peña II (Cáseda) y Bartullo I (Cáseda). De ellos destaca especialmente el primero, pues se emplaza al pie de la actual Cañada Real de los Roncaleses que permite un acceso rápido al interior de la sierra. En relación con ello cabe preguntarse si esta orientación hacia el oeste pudo estar relacionada con la búsqueda y control de una ruta más amable hacia los recursos cupríferos del norte de la sierra.

22 Si bien las rutas óptimas tienen un alto grado de parcialidad por cuanto que los datos sobre los que se basan, especialmente los ambientales, suelen ser contemporáneos (López Romero, 2005, pp. 108-109) consideramos que constituyen una interesante herramienta de apoyo a la interpretación de la dispersión de material aislado en el campo, aunque en ningún caso deben considerarse concluyentes y sus resultados deben ser tomados con cautela. En nuestro caso para llevar a cabo las rutas óptimas se ha utilizado el programa QGIS en el que se han empleado tres fuentes distintas: mapa hidrológico de la zona; mapa digital del terreno (MDT05 hojas $174 \mathrm{y}$ 207) y un mapa de uso de suelos que son de utilización obligatoria como mínimo para elaborar un mapa de estas características (i. e. López Romero, 2005, pp. 99-105; Van Lanen, Kosian, Groenewoudt, Spek \& Jansma, 2015, pp. 146-153). Siguiendo otros ejemplos (López Romero, 2005 , p. 100) se trataron las curvas de nivel del mapa digital del terreno eliminándose aquellos elementos modernos como caminos, puentes o el actual Canal de las Bardenas que pudieran distorsionar los datos. La revalorización de los ríos se obtuvo de Lopez Romero (2005, pp. 102103), mientras que la pendiente obtenida del MDT se revalorizo siguiendo a Llobera (1999, pp. 77-80). Por último, para calcular la dificultad que pudo ofrecer la vegetación (coste energético de desplazamiento) se ponderó por medio de una escala del 1 al 9, siendo 1 la más fácil y 9 la más difícil. 


\section{CONCLUSIONES}

A modo de conclusión puede ser interesante recoger las principales ideas que se han ido mostrando a lo largo del presente trabajo.

No cabe duda de que para la identificación de las pautas de ocupación del territorio se ha partido de un modelo del ser humano netamente rousseano, pero que no se nos oculta que descansa sobre bases endebles, incrementadas por la propia caracterización del material de estudio. Los problemas conceptuales para esta época son muchos y en ocasiones irresolubles. En nuestro caso desde el punto de vista de la arqueología del paisaje cabe preguntarse en qué momento la interconexión entre las distintas áreas de vida de las comunidades en cuestión logró formar un territorio. Esta cuestión, relativamente fácil de caracterizar en épocas posteriores, se torna complicada para este momento pues todo ello descansa en la relación entre sitios en el instante de la sedentarización. ¿Son independientes las comunidades neolíticas previas al periodo que estamos tratando? De ser así, ¿Puede el presumible auge de unos sitios coincidente con el menor desarrollo, cuando no desaparición, de otros expresar una noción de competencia por los recursos naturales siendo fruto de una acción premeditada? Por el contrario, ¿La presencia de sitios en lugares estratégicos del territorio, tanto de control visual como de paso, puede ser el resultado de una actitud consciente de posesión de los recursos por parte de un único grupo? Es precisamente esta última línea interpretativa la que subyace en estas páginas.

Pero, además, la existencia de un único grupo coherente, al menos en el Calcolítico, permite la identificación de una dimensión visible, material y funcional del proceso de ocupación del territorio, aspectos tratados en estas páginas, de tal forma que el lugar donde se emplaza el sitio es el resultado de una decisión activa de la comunidad (Rizvi, 2013, p. 317). Además tampoco se puede olvidar la existencia de otros elementos vinculados al imaginario y al deseo colectivo que condicionarían esta ocupación (i.e. Anschuetz et al., 2001; Rubenstein, 2012), si bien desconocemos cuáles podrían ser, aun cuando durante la prospección en campo se trataron de identificar.

De forma general puede considerarse que el conjunto de nueve sitios que compone el grupo de Peña se caracteriza por tratarse de sitios no demasiado grandes en superficie y número de piezas recuperadas. Se emplazan en la mayor parte de los casos en lo alto de pequeñas colinas, normalmente a una altura media de unos $17 \mathrm{~m}$ sobre el nivel del valle y cercanos a una fuente de agua. La producción lítica recuperada está caracterizada por tratarse de sílex evaporítico de origen desconocido, en cualquier caso de zonas periféricas y se determina por un mayor peso de las lascas con respecto a las láminas.

De todos estos sitios sobresale tanto por la cantidad de artefactos como por tamaño y control visual el sitio de Peña X (n. $\left.{ }^{\circ} 2\right)$, no descartándose que fuera el principal sitio de la zona. Junto a él quizá se desarrollaron otros sitios estables ( $\mathrm{n}^{\circ \mathrm{s}} 3,4,5$ y 6 ) bien como continuación de los antiguos espacios neolíticos o bien fruto de la propia expansión demográfica calcolítica, destacando de entre ellos el sitio de Peña XIII (n. ${ }^{\circ}$ 5). La relación entre Peña XIII y Peña X resulta de gran interés por cuanto que el primero arranca en el Neolítico, no descartándose que fuera un sitio de primer orden en ese periodo, mientras 
que el segundo constituye un nuevo asentamiento creado como consecuencia de las nuevas necesidades de este grupo humano. Por desgracia las características del material con el que se trabaja impiden ahondar en una línea que, sin duda, solo futuras actuaciones arqueológicas podrán aclarar.

En cualquier caso, en general puede considerarse que los nueve sitios calcolíticos identificados surgen en respuesta a la existencia de un nicho económico regional que, posiblemente, muestra su época de mayor esplendor en torno al segundo milenio a. C. Ello quizá condujo a una cierta sedentarización del grupo humano, pues al menos la mitad de los sitios conocidos pueden considerarse, con prudencia, lugares estables, lo cual a su vez llevó a conformar una cierta estructuración del territorio. Dentro de esta organización del territorio parecen conformarse, a modo de hipótesis, los barrancos de Valdelasviñas y Pintanés como ejes de comunicación de la zona, especialmente hacia el sur. Además, la búsqueda de los recursos cupríferos situados al norte de las sierra de Peña pudo ser el causante de la presencia de un eje de comunicación hacia el oeste, en dirección a la Val de la Cañada, que no solo podría tener como objetivo el río Aragón, sino también la búsqueda de una ruta más fácil hacia los afloramientos de cobre.

De ser correctas estas vías de comunicación, quizá pueda considerarse que el grupo de Peña no solo podría ser una comunidad enfocada hacia labores agrícolas y, tal vez, cinegéticas, sino que se constituiría en un grupo humano para el que la obtención de los recursos cupríferos parece cobrar una singular importancia.

En contraste la parte oriental del territorio se muestra sorprendentemente vacía, aun cuando su control visual es muy amplio, lo cual denota el interés de este grupo por este espacio. La presencia, si bien todavía escasamente conocida, de un segundo grupo humano y la necesaria relación entre ambos quizá podría explicar este vacío. Sin embargo, en el estado actual de la investigación todavía es prematuro realizar cualquier tipo de hipótesis sobre los vínculos que pudieron tener ambos grupos, aunque no deja de ser significativo el vacio poblacional existente entre ambos.

Queda así, para finalizar, caracterizado el grupo de Peña como un singular conjunto de sitios de cronología calcolítica que permiten plantear, a modo de hipótesis, la existencia de una primera jerarquización de este territorio. Lógicamente quedan muchas preguntas en el aire, como la relación de este grupo con las comunidades vecinas o su repentina desaparición durante el Bronce. Por desgracia comprender todo ello excede con creces los límites de este trabajo y del conocimiento actual de la ocupación de la zona. En cualquier caso, solo futuras intervenciones permitirán ir poco a poco completando el mosaico de ocupación y uso de un espacio en una época tan apasionante como esta.

\section{LISTA DE REFERENCIAS}

Andrés, T. (1977). Las estructuras funerarias del Neolítico y Eneolítico en la Cuenca Media del Ebro. Consideraciones críticas. Príncipe de Viana, 146-147, 65129. 
Andrés, T. (1978). Estudio tipológico-arquitectónico de los sepulcros del Neolítico y Calcolítico de la cuenca media del Ebro, Zaragoza: Universidad de Zaragoza.

Andrés, T. (1979). Ritos funerarios de la cuenca media del Ebro: Neolítico y Eneolítico. Berceo, 97, 1-24.

Andrés, T. (1986). Sobre cronología dolménica: País Vasco, Navarra y La Rioja. En Estudios en homenaje al Dr. Antonio Beltran Martinez (pp. 237-265). Zaragoza: Universidad de Zaragoza.

Anschuetz, K. F., Wilshusen, R. H. \& Scheick, Ch. L. (2001). An Archaeology of Landscapes: Perspectives and Directions. Journal of Archaeological Research, 9(2), 152-197.

Aranzadi, T. \& Ansoleaga, F. (1915a). Exploración de cinco dólmenes de Aralar. Boletín de la comisión de Monumentos Históricos y Artísticos de Navarra, 21, 28-39.

Aranzadi, T. \& Ansoleaga, F. (1915b). Exploración de cinco dólmenes de Aralar. Boletín de la comisión de Monumentos Históricos y Artísticos de Navarra, 22, 89-104.

Aranzadi, T. \& Ansoleaga, F. (1915c). Exploración de cinco dólmenes de Aralar. Boletín de la comisión de Monumentos Históricos y Artísticos de Navarra, 23, 157-169.

Aranzadi, T. \& Ansoleaga, F. (1915d). Exploración de cinco dólmenes de Aralar. Boletín de la comisión de Monumentos Históricos y Artísticos de Navarra, 24, 209-227.

Aranzadi, T. \& Ansoleaga, F. (1918). Exploración de catorce dólmenes de Aralar. Pamplona: Imprenta provincial.

Aranzadi, T., Barandiarán, J. M. \& Eguren, E. (1920). Exploración de siete dólmenes de la sierra de Ataun-Burunda. San Sebastian: Imp. de la Provincia.

Aranzadi, T., Barandiarán, J. M. \& Eguren, E. (1921). Exploración de ocho dólmenes de la Sierra de Alzania. San Sebastián: Imp. de la Provincia.

Aranzadi, T., Barandiarán, J. M. \& Eguren, E. (1923). Exploración de seis dólmenes de la Sierra de Urbasa (Navarra). San Sebastian: Imp. de la Provincia.

Armendáriz Gutiérrez, A. (1997). Neolítico y Calcolítico en el País Vasco peninsular. Isturitz, 7, 23-36.

Armendáriz Martija, J. (1999). El Megalitismo en Navarra: dólmenes de Artajona. Revista de Arqueología, 218, 24-37.

Armendáriz Martija, J. (2008). De aldeas a ciudades: El poblamiento durante el primer milenio a. C. en Navarra. Pamplona: Gobierno de Navarra.

Armendáriz Martija, J. \& Irigaray Soto, S. (1991-92). Aportación al estudio de los yacimientos líticos postpaleolíticos al aire libre en Navarra. Zephyrus, 44-45, 223-239.

Barandiarán, I. \& Cava, A. (1981). Neolítico y Eneolítico en las provincias de Teruel y Zaragoza. En I Reunión de Prehistoria Aragonesa (pp. 98-100) Huesca: Ministerio de Cultura.

Barandiarán, I. \& Vallespi, E. (1982). Prehistoria de Navarra. Trabajos de Arqueología Navarra, 3, 1-241. 
Barandiarán, J. M. (1926). Estaciones Megalíticas en Navarra. Revista Internacional de Estudios Vascos, 17, 358-368.

Barandiarán, J. M. (1962). En el Pirineo vasco. Prospecciones y excavaciones prehistóricas. Munibe, 11, 297-378.

Barton, C. M., Bernabeu, J., Aura, J. E., Garcia, O. \& La Roca, N. (2002). Dynamic landscapes, artifact taphonomy, and landuse modeling in the western Mediterranean. Geoarcheology, 17(2), 155-190.

Beguiristáin, M. A. (1976). Excavación en el dolmen de Miruatza (Echarri-Aranaz, Navarra). Principe de Viana, 144-145, 365-374.

Beguiristáin, M. A. (1979). Cueva del nacedero de Riezu, valle de Yerri. Trabajos de Arqueología Navarra, 1, 91-101.

Beguiristáin, M. A. (1980). Los yacimientos de habitación durante el Neolítico y la Edad de Bronce en el alto valle del Ebro (tesis doctoral inédita). Universidad de Navarra, Pamplona.

Beguiristáin, M. A. (1982). Los yacimientos de habitación durante el Neolítico y Edad del Bronce en el Alto Valle del Ebro. Trabajos de Arqueología Navarra, 3, 59-156.

Beguiristáin, M. A. (1987). Lesiones patológicas en la población del Abrigo del Padre Areso (Bigüezal, Navarra). Zainak. Cuadernos de Antropología-Etnografía, 4, 125-132.

Beguiristáin, M. A. (1990). El hábitat del Eneolítico a la Edad del Bronce en Álava y Navarra. Munibe, 42, 125-133.

Beguiristáin, M. A \& Albisu, C. (2003). La población del dolmen de Aizbitia (Cirauqui, Navarra): avance de la analítica aplicada a los restos óseos humanos. Cuadernos de Arqueología de la Universidad de Navarra, 11, 81-90.

Beguiristáin, M. A., Vélaz, D., Unanua, R. \& Álvarez, E. (2007). Una estructura megalítica inédita en la cuenca del río Arga: el yacimiento de Sotoaldea (Mañeru, Navarra). Caesaraugusta, 78, 135-144.

Bernabeu, J., Aura, J. E. \& Badal, E. (1993). Al oeste del Edén. Las primeras sociedades agrícolas en la Europa Mediterránea. Madrid: Síntesis.

Burillo, F., Ibáñez, J. \& Alegre, E. (2005). Prospección y concepto de asentamiento. El caso de la ciudad celtibérica de Segeda. Arqueología Espacial, 24-25, 165-184.

Butzer, k. W. (2007). Arqueología, una ecología del hombre. Método y teoría para un enfoque contextual. Barcelona: Bellaterra.

Cabello García, J. (2005). El poblamiento humano prehistórico de las Cinco Villas (Zaragoza). Nuevas vías de aproximación al estudio de los yacimientos líticos de superficie de la prehistoria reciente. El sistema analítico de evaluación habitacional (S. A. E. H.): propuesta metodológica. Salduie, 5, 9-56.

Cava, A. (1984). La Industria lítica en los dólmenes del País Vasco meridional. Veleia, $1,51-156$.

Cava, A. (1986). La industria lítica de la Prehistoria reciente en la cuenca del Ebro. Boletín del Museo de Zaragoza, 5, 5-72.

Cava, A. \& Beguiristáin, M. A. (1991-92). El yacimiento prehistórico del abrigo de la Peña (Marañon, Navarra). Trabajos de Arqueología Navarra, 10, 69166. 
Chapman, R. (1991). La formación de las sociedades complejas. El sureste de la Península Ibérica en el marco del Mediterráneo occidental. Barcelona: Crítica.

Deetz, J. (1990). Landscapes as cultural statements. En W. M. kelso \& R. Most (eds)., Earth Patterns: Essays in Landscape Archaeology (pp. 2-4). Charlottesville \& London: University of Virginia.

Edeso, J. M. \& Mujika, J. A. (2017). Estudio de patrones espaciales y de reconstrucción paisajística mediante el uso de sistemas de información geográfica (Praileaitz I, Deba, Gipuzkoa), Munibe, 1, 171-191.

Elosegui, J. (1952). Nuevos dólmenes navarros (Urbasa, Andia, Sarbil). Pyrenaica, 4, 118-123.

Elosegui, J. (1953a). Nota previa acerca de siete nuevos dólmenes. Munibe, 5, 21.

Elosegui, J. (1953b). Catálogo dolménico del País Vasco. Pirineos, 28-30.

Elosegui, J. (1962). Siete nuevos dólmenes en Navarra. Munibe, 14, 359-369.

Ember, C. R., \& Ember, M. (1972). The Conditions Favoring Multilocal Residence. Southwestern Journal of Anthropology, 28, 382-400.

Erce Domínguez, A. \& Unánua González, R. (2013). Autovía del Pirineo, tramos 4 y 5. La protección del patrimonio arqueológico. Trabajos de Arqueología Navarra, 25, 171-182.

Ezkurdia, M. (1987). Dólmenes no catalogados en Navarra. Gorosti, 4, 84.

García Gazólaz, J. (1993). Saso I y II: reflejos de una economía de producción durante el Eneolítico Final-Bronce Antiguo en Navarra. Cuadernos de Arqueología de la Universidad de Navarra, 1, 17-52.

García Gazólaz, J. (1998). Paternanbidea (Ibero, Navarra): un yacimiento al aire libre de la prehistoria reciente de Navarra. Cuadernos de Arqueología de la Universidad de Navarra, 6, 33-48.

García Gazólaz, J. \& Sesma Sesma, J. (2009). La tecnología laminar del sílex durante el Neolítico-Calcolítico en Navarra: una primera aproximación. En J. F. Gibaja Bao \& X. Terradas Batlle (coords.), Les grans fulles de sílex Europa al final de la prehistòria: actes (pp. 83-88). Barcelona: Museu d'Arqueologia de Catalunya.

Gillings, M. (2015). Mapping Invisibility: GIS approaches to the analysis of hiding and seclusion, Journal of Archaeological Science, 62, 1-14.

Gomes de Mello, A. (2001-02). Destruído pelo arado? Arqueologia de superfície e as armadilhas do senso comum. Revista de Arqueologia, 14-15, 7-28.

Grau Mira, I., Carreras Monfort, C., Molina Vidal, J., De Soto, P. \& Segura Martí, J. M. (2012). Propuestas metodológicas para el estudio del paisaje rural antiguo en el área central de la Contestania. Zephyrus, 70, 131-149.

Hodder, I. \& Orton, C. (1990). Análisis especial en arqueología. Barcelona: Crítica.

Irigaray, S. \& Armendáriz, J. (1993-94). Resumen de las excavaciones arqueológicas en el Hipogeo del Longar (Viana, Navarra): (1991-1993). Trabajos de Arqueología Navarra, 11, 270-275.

Irigaray, S. \& Armendáriz, J. (1995). Violencia y muerte en la prehistoria: el Hipogeo del Longar (Viana, Navarra). Revista de Arqueologia, 168, 16-29.

Iturralde y Suit, J. (1911). Monumentos megalíticos en Navarra. Boletín de la Real Academia de la Historia, 58, 197-215. 
Jordán, Á. A. (2018a). Larraz: Una villa periurbana en el entorno de Cabeza Ladrero (Sofuentes/Sos del Rey Católico, Zaragoza). En J. I. Lorenzo Lizalde \& J. M. Rodanés Vicente (eds.), II CAPA. Actas del II Congreso de Arqueología y Patrimonio Aragonés (Zaragoza, 9 y 10 de noviembre de 2017) (pp. 269-279). Zaragoza: Colegio Oficial de Doctores y Licenciados en Filosofía y Letras y en Ciencias de Aragón.

Jordán, Á. A. (2018b). El Proyecto Arqueológico de Cabeza Ladrero. En J. I. Lorenzo Lizalde (ed.), Actas del Congreso Nacional de Arqueología Profesional (Zaragoza, 4, 5 y 6 de abril de 2017) (pp. 103-112). Zaragoza: Colegio Oficial de Doctores y Licenciados en Filosofía y Letras y en Ciencias de Aragón.

Jordán, Á. A., Pérez López, L. \& Rodríguez Hermoso de Mendoza, M. (2021). Nuevos datos sobre la ocupación neolítica al sur de la sierra de Sos (Sos del Rey Católico, Zaragoza). Archéologie des Pyrénées Occidentales et des Landes, 32, 29-36.

Lamprecht H. (1990). Silvicultura en los trópicos: los ecosistemas forestales en los bosques tropicales y sus especies arboreas. posibilidades y métodos para un aprovechamiento sostenido. Eschborn: Paul Parey.

Leveau, P. (2000). Du site au réseau: archéologie, géographie spatiale oú géographie historique. En M. Pasquinucci \& F. Trément (eds.), Non-Destructive Techniques Applied to Landscape Archaeology. The Archaeology of Mediterranean Landscapes (pp. 272-276). Oxford: F. Trement.

López Astilleros, K. M. (1993). El poblamiento desde el Calcolítico a la Primera Edad del Hierro en el Valle Medio del Río Tajo. Complutum, 4, 321-336.

López Romero, R. (2005). Cálculo de rutas óptimas mediante SIG en el territorio de la ciudad celtibérica de Segeda. Propuesta metodológica. Salduie, 5, 95-111.

López Selles, T. (1957). Nuevos hallazgos dolménicos en Navarra. Munibe, 9, 105- 112.

López Selles, T. (1959a). Aportación al catálogo dolménico del País Vasco: sector Idokorri-Ugarra. Munibe, 11, 20-26.

López Selles, T. (1959b). Aportación al catálogo dolménico del País Vasco: sectores Baztán-Bertizarana y Leyre-Illón. Munibe, 11, 107-109.

López Selles, T. (1960). Nuevos hallazgos dolménicos en Navarra. Munibe, 13, 246250.

López Selles, T. (1961). Nuevos dólmenes y cromlechs navarros. Munibe, 13, 286-290.

Llobera, M. (1991). Understanding movement: a pilot model towards the sociology of movement. En G. R. Lock (ed.), Beyond the map: archaeology and spatial technologies (pp. 65-84). Amsterdam: IOS.

Maluquer, J. (1955). Prospecciones Arqueológicas en término de Navascués. Príncipe de Viana, 60, 285-304.

Maluquer, J. (1962). Notas sobre la cultura megalítica en Navarra. Príncipe de Viana, 92-93, 93-147.

Maluquer, J. (1964). Sepulcros megalíticos navarros con puerta perforada. VIII Congreso Nacional de Arqueología (Sevilla-Málaga, 1963) (pp. 234-242). Zaragoza: Universidad de Zaragoza.

Maluquer, J. (1965). Arquitectura megalítica pirenaica. En Arquitectura megalítica y ciclópea catalanobalear (pp. 25-40). Barcelona: CSIC. 
Marcos Sáiz, F. J. \& Díez Fernández-Lomana, J. C. (2009). Primeros resultados de la evolución del poblamiento en el entorno de la sierra de Atapuerca desde el Neolítico a la Edad del Bronce. En Actas del congreso Medio siglo de arqueología en el Cantábrico Oriental y su entorno (pp. 777-790). Vitoria: Diputación Foral de Álava \& Instituto Alavés de Arqueología.

Mayoral Herrera, V., Cerrillo Cuenca, E. \& Celestino Pérez, S. (2009). Métodos de prospección arqueológica intensiva en el marco de un proyecto regional: el caso de la comarca de La Serena (Badajoz). Trabajos de Prehistoria, 66(1), 7-26.

Martín Fernández, A. (2014). Los dientes de hoz de la Meseta Leonesa: el sitio de «Las Choperas». En J. Honrado Castro, M. Á. Brezmes Escribano, A. Tejeiro Pizarro, Ó. Rodríguez Monterrubio (eds.), Investigaciones arqueológicas en el valle del Duero. Vol 2: Neolítico y Calcolítico en el valle del Duero (pp. 129-149). Glyphos.

Montes, L. \& Domingo, R. (2014). La ocupación de las sierras exteriores durante el Calcolítico. En P. Utrilla \& C. Mazo (eds.), La Peña de las Forcas (Graus, Huesca). Un asentamiento estratégico en la confluencia del Ésera y el Isábena (pp. 409-426). Zaragoza: Prensas Universitarias de Zaragoza.

Nuin Cabello, J. \& Borja Simón, J. A. (1991). El poblamiento holocénico y su medio en las cuencas prepirenaicas de Pamplona y Aoiz-Lumbier. Isturitz, 4, 61-96.

Ondarra, F. (1975a). Nuevos monumentos megalíticos en Baztán y zonas colindantes. Príncipe de Viana, 138-139, 5-46.

Ondarra, F. (1975b). Nuevos monumentos megalíticos en Baztán y zonas colindantes II. Príncipe de Viana, 142-143, 403-433.

Ondarra, F. (1976a). Nuevos monumentos megalíticos en Baztán y zonas colindantes III. Principe de Viana, 142-143, 21-54.

Ondarra, F. (1976b). Nuevos monumentos megalíticos en Navarra. Príncipe de Viana, 144-145, 329-363.

Ondarra, F. (1982). Nuevos monumentos en Navarra (II). Príncipe de Viana, 165, 7-32.

Ondarra, F. (1988). Nuevos monumentos en Navarra (III). Trabajos de Arqueología Navarra, 7, 119-143.

Ondarra, F. (1991-92). Noticias megalíticas en los papeles de Tomás López Sellés. Trabajos de Arqueología Navarra, 10, 167-183.

Ortiz Tudanca, L. (1990). Ordenación de la secuencia cultural del Calcolítico y la Edad del Bronce en el País Vasco. Munibe, 42, 135-139.

Pardo-Gordó, S. et al. (2017). Segunda campaña de prospección en el territorio inmediato a cueva Cocina: El Valle del Magre. Saguntum, 49, 187-190.

Peña, L. (1954). Varios nuevos monumentos en Guipúzcoa y Navarra. Munibe, 6, 174181.

Ramos Aguirre, M. (2009). Arqueología en la Autovía del Camino. Trabajos de Arqueología Navarra, 21, 5-119.

Ramos Muñoz, J., Valverde Lasanta, M., Romero Sánchez, J. L. \& Almagro Blázquez, A. (1991). La tecnología lítica de la transición del Neolítico a la Edad del Cobre en la zona centrooccidental de Cádiz. Zephyrus, 44, 207-221.

Renfrew, C. \& Bahn, P. (2013). Arqueología. Teorías, métodos y prácticas. Madrid: Akal. 
Ripa, P. (1952). Sierra de Illón. Pyrenaica, 1, 17-18.

Rizvi, U. Z. (2013). Crafting communities and producing places: Copper, settlement patterns, and social identity in the Ganeshwar Jodhpura Cultural Complex, Rajasthan, India. En S. A. Abraham, P. Gullapalli, T. O. Raczek \& U. Z. Rizvi (eds.), Connections and Complexity: New Approaches to the Archaeology of South Asia (pp. 315-340). Walnut Creek: Left Coast Press.

Rubenstein, S. (2012). On the importance of visions among the amazonian shuar. $\mathrm{Cu}$ rrent Anthropology, 53(1), 39-79.

Sansinenea, J. M. (1950). Formaciones megalíticas en los montes Ezcurra (Navarra), en el paraje Ezkain y en el monte Elazmuño. Munibe, 11, 7-10.

Schlanger, S. (1992). Recognizing persistent places in Anasazi settlement systems. En J. Rossignol \& L. Wandsnider (eds.), Space, Time and Archaeological Landscapes (pp. 91-112). New York: Springer.

Sesma Sesma, J., Andrés Rupérez, M. T. \& García García, M. L. (1997). El sepulcro calcolítico de Tres Montes (Las Bardenas Reales, Navarra). En P. Bueno Ramírez \& R. de Balbín Behrmann (coords.), II Congreso de Arqueología Peninsular: Zamora, del 24 al 27 de septiembre de 1996 (vol. 2., pp. 301308). Zamora: Fundación Rei Afonso Henriques.

Sesma Sesma, J. \& García García, M. L. (2006). Llanos de Escudero II. Una cista de la Edad del Bronce en las Bardenas Reales de Navarra. Revista del Centro de Estudios Merindad de Tudela, 14, 7-24.

Sesma Sesma, J. \& García García, M. L. (2012). Dos sepulturas tumulares de la Edad del Bronce en Navarra. Cuadernos de Arqueología de la Universidad de Navarra, 20, 185-216.

Sesma Sesma, J., García García, M. L., Beguiristáin, M. A. \& Sinues del Val, M. (19931994). Excavación en el dolmen de Aizibita (Cirauqui, Navarra). Trabajos de Arqueología Navarra, 11, 265-269.

Sesma Sesma, J., García García, M. L., Herrero Corral, A. M., Moreno García, M., Pérez Díaz, S., Ruiz, M. \& López Sáez, J. A. (2014). Caracterización y cronología de un yacimiento de la Edad del Bronce: San Pelayo IV, Arellano (Navarra). Trabajos de Arqueología Navarra, 26, 99-202.

Sesma Sesma, J. \& García Gazólaz, J. (1995-96). Excavación de urgencia en los yacimientos de depósitos en Hoyos de Aparrea (Biurrun) y La Facería (Tiebas). Trabajos de Arqueología Navarra, 12, 293-297.

Sesma Sesma, J. (coord.), López Quintana, J. C., Mujika Alustiza, J. A., Rodanés Vicente, J. M. \& Vegas Aramburu, J. I. (2009). El período Calcolítico-Edad del Bronce en el Cantábrico oriental y su entorno. En Actas del congreso «Medio siglo de arqueología en el Cantábrico Oriental y su entorno» (pp. 115-200). Vitoria: Diputación Foral de Álava \& Instituto Alavés de Arqueología.

Terrenato, N. (2001). Yacimiento/No yacimiento. En R. Francovich \& D. Manacorda (eds.), Diccionario de Arqueología (pp. 364-365). Barcelona: Crítica.

Terrenato, N. (2004). Sample size matters! The paradox of global trends and local surveys. En S. E. Alcock \& J. F. Cherry (eds.), Side-by-side Survey: Comparative Regional Studies in the Mediterranean World (pp. 36-48). Oxford: Oxbow. 
Unanua González, R. \& Erce Domínguez, A. (2014). Aportes al conocimiento de los yacimientos al aire libre, nuevos campos de hoyos en Navarra. Cuadernos de Arqueología de la Universidad de Navarra, 22, 73-118.

Utrilla, M. P. (1977). Excavaciones en la Cueva de Abauntz (Arraiz): campaña de 1976. Príncipe de Viana, 147-148, 47-64.

Utrilla, M. P. (1979). Excavaciones en la cueva de Abauntz (Arraiz): campaña de 1977. Trabajos de Arqueología Navarra, 1, 61-71.

Utrilla, M. P. (1982). Yacimiento de la Cueva de Abauntz (Arraiz, Navarra). Trabajos de Arqueología Navarra, 2, 203-345.

Van Lanen, R. J., Kosian, M. C., Groenewoudt, B. J., Spek, Th. \& Jansma, E. (2015). Best travel options: modelling roman and early-medieval routes in the Netherlands using a multi-proxy approach. Journal of Archaeological Sciencie: Reports, 3, 144-159.

Van Lanen, R. J. \& Pierik, H. J. (2017). Calculating connectivity patterns in delta landscapes: Modelling Roman and early-medieval route networks and their stability in dynamic lowlands. Quaternary International, 502, part B, 393-412. Doi:https://doi.org/10.1016/j.quaint.2017.03.009

VV. AA. (2001). Inventario Arqueológico de Navarra. Javier, parcial. Pamplona, inédito.

Vallespí, E. (1975). Investigacion de la prehistoria de Navarra: historiografia y bibliografía. Príncipe de Viana, 138-139, 47-82.

Walker, R. S., Hamilton, M. J. \& Groth, A. A. (2014). Remote sensing and conservation of isolated indigenous villages in Amazonia. R. Soc. Open Sci. 1:140246, DOI: https://doi.org/10.1098/rsos.140246

Witcher, R. E. (2006). Broken Pots and Meaningless Dots? Surveying the Rural Landscapes of Roman Italy. Papers of the British School at Rome, 74, 39-72.

90 Trabajos de Arqueología Navarra (TAN), 31-32, 2019-2020, 57-90

ISSN: 0211-5174 ISSN-e: 2530-5816 ISSN-L: 0211-5174 